\title{
21.
}

\section{Millensfreibeit und strafreigt.}

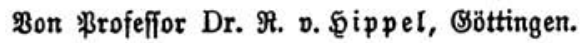

Die folgenton \$lätter geben einen $\mathfrak{B o r t r a g}{ }^{1}$ ) mieber, weldjen i. im Dezember 1902 in ber pindjologif $=$ =forenfifden Bereinigung zu (Böttingen hielt ${ }^{2}$ ).

3ur Druđ̆legung babe id mid entidlofien, nidit in ber $\mathscr{2}_{11}=$ nahme auj biejem viel erörterten un beiß umftrittenen SSebiete übermiegento neues leiften zu tömen, wohl aber in ber Soffiumg, zur Slärung ber Disłtuffion beizutragen uno in bem Bedürfuię, meine perjönlide Deinumg hinfidtlidy einer ber Brrumbfragen meines

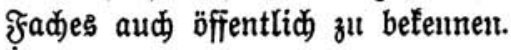

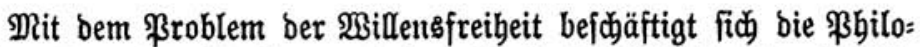

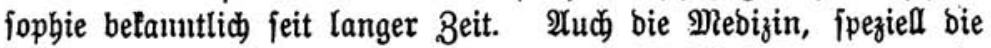
\$indiatrie, bat fid jeiner Erforidung wiffenidaftlid zugemandt

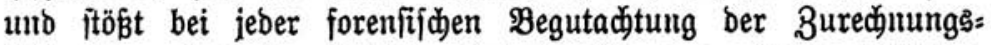
fäbigteit auf bas geieb̧lide Erforbernis ber "freien \$illens: bejitimunung". F̈ür bas Straf̣redt eltolid ftellt unjer \$roblent heute eine ber am lebbajteften erörterten uno umftrittenen SBrunb= fragen bar.

(F) hanbelt fich für ben Sriminalijten un folgento mifienfidjaft: (id) uno zugleid praftifd hodmidtige Frage: Sind bie -\$be= gefügt.

1) Bur befferen Drientierung find einige ertäuternie Inmertungen ginzus

2) Die Bereinigung beftegt auฐ \$hilofophen, \$ledizinern und Suriften, Theoretifern wie \$raftifern. Sie wurbe in Sommer 1902 von den \$rofefforen

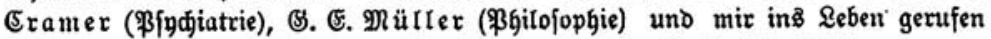

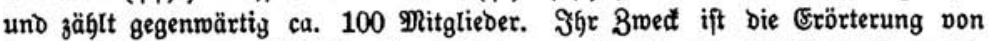

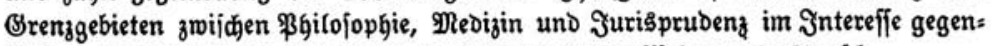

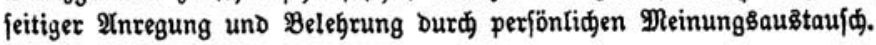




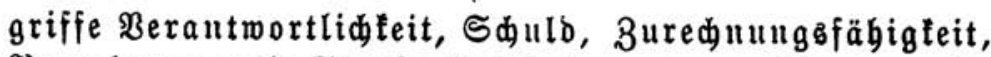
Bergeltung unb Strafe haltbar uur vom Staubpuntte ber Billensireibeit aus? Wenn ja, fo muв bas Strafredt fid entweber auf biejen Stanbpuntt ftellen, ober, weml es ign für falich bält, fo mur es jene (Brumbbegriffe, auj meldent es beute fubt, über $\mathscr{B}$ orb merfen und einen völlig neuen 2 ufbau verfuden.

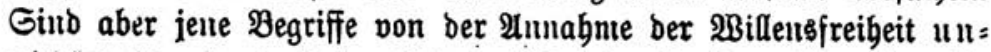
abbängig, fo Darf ber Sriminalijt feine hentigen Brunobegriffe beibebalten unb fid benuod zum Determinismus betennen. Doer er barf es madell, wie feine zivilredtlide Sdimeftermiffentidaft es bei ber Regre von ber privatredtliden Berantwortlideteit für \{dulbbaftes Sanbeln thut: er barf bie galize frage ber æillens: freibeit ober =Unifreibeit überhaupt igutorieren als eitre rein philo:

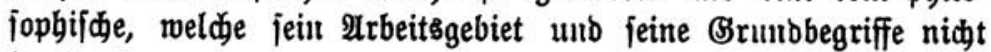
berübrt ${ }^{3}$ ).

3) 3n bcr \&itteratur wiro bismeilen nod eine andre Steflungnagme Des

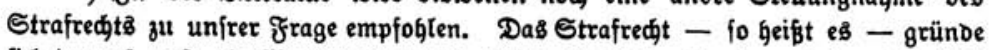

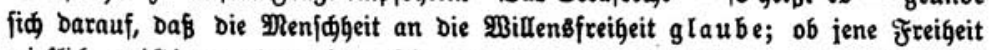
mirtlid eriftiere oder nidt, fei demgegenüber gleidgiltig. Iో galte diejen

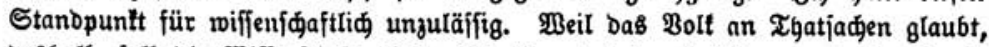

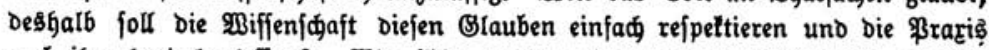

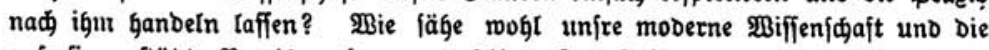

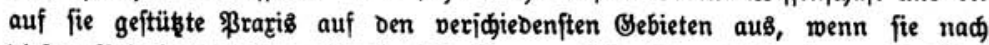
biefem \$rinzip verfabren märe? Die Sonne würbe fit nod beute um die Erbe

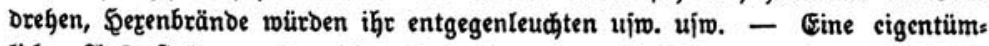

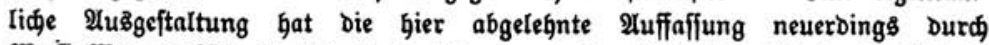

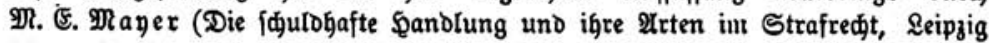
1901, S. 92-101) erfagren: Der פeníl ift nad פlayer allerdings willens:

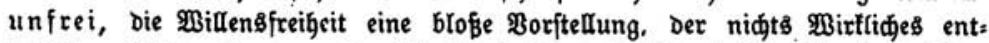

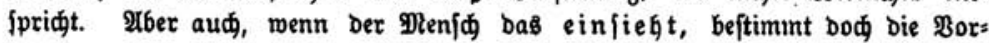

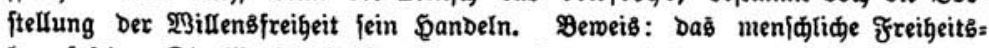

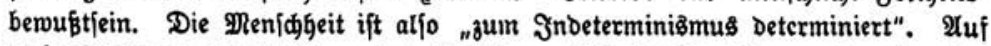

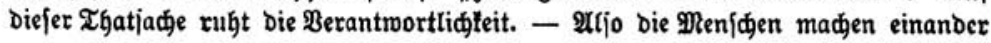

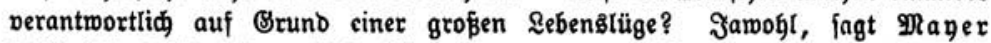

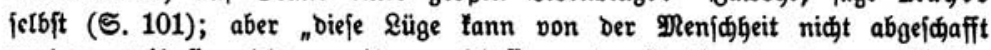
merben, weil fie nidt von igr angeidafft wurbe, fie liegt in ber menífliden

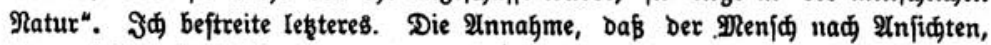

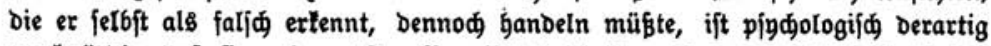

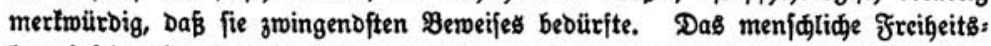
bemuftfein aber beweift niळts Derartiges und bie angeblide menjळlide unfä̧ig:

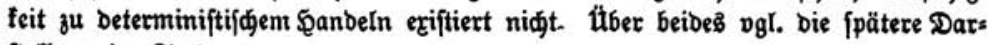
ftellung im rext. 
$\mathfrak{H}_{m}$ Die Ronjequenzen bes Determinisnuts ober Sndeterminis= mus zu unterfuden, ift zumädit möglidjit fdharf feitzuftellen: Worin beitegt ber Begenlą beiber? $\mathfrak{B a n n}$ ift aljo ientanb Deter= minift und waun ungefehrt Bertreter ber Billens= freikeit? Diefe Feftiteflumg ift um fo notwendiger, als in ber Geutigen \&itteratur bas $\mathfrak{B o r t}$ "Willentefreifeit" in mehrjacher $\mathfrak{B e}=$ Deutung vorfoumt uno als nud) foult bäufig Untlarbeiteu über ben Begenjał bejtehen, veldje zu gegenjeitigen Mifßveritänoniffẹt ge= jübrt Gaben.

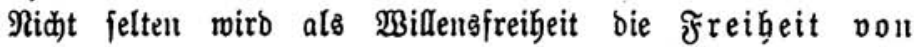
äußerem Zुmang bezeidjnet. Şn biejem Sinme frei aber ijt jelbit: verfänolid jeder Dienlid), fofern er nidt ausnabmsmeife burd) ab: jolute Bewalt, burd Drohungen ober fonitige Rotlagen, weld)e jeinen Bideritano breden, zu cinem beftinmten törperliden $\mathfrak{\text { Ber: }}$ Galten veranlajt wird*). Mit unjer Sontroverje bat bieje frei=

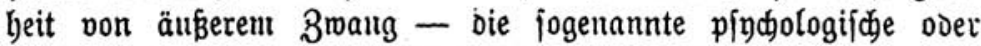
\$andhurgfreibeit - aljo überbaupt nidjts zu thum.

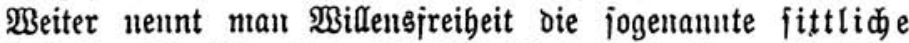

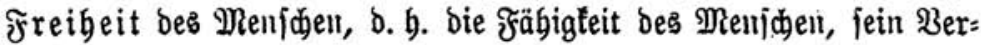

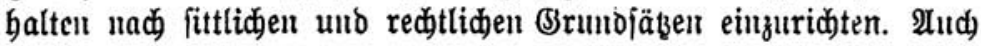
bieje fittlide Freibeit ift gämzlid unbejtreitbar uno unbejtrittent, jofern fic leoiglid) eine im allgemeiner, o. h. aljo gemöhnlid),

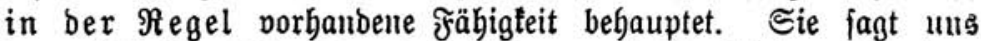

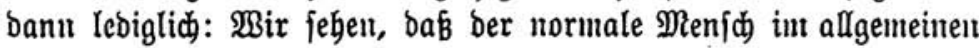
reçtmäßig hanbelt; und baraus folgern wir, baß̄ er audj ìn all= gemeinen bazı fähig ift. Nun feben mir aber betamutlid) auch,

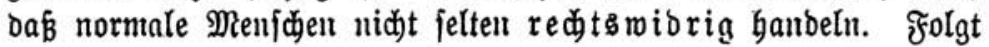

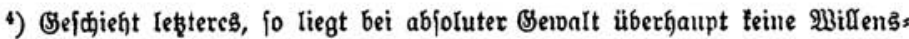
hanolung uno beş̧alb jelbftterftändtic feine Berantwortlidfeit vor. Bei Drohun= gen oder fonftigem Notftand aber beftimunt Das pofitive Mect, wann Die Ber= antmortlidfeit ausige genneine Erwvägung, waş man erfałrungs̊gemäß von einem riđjtlich Denfendẹn

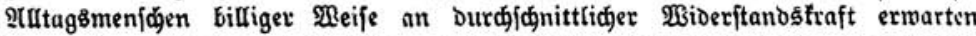

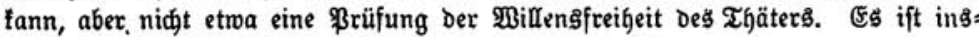

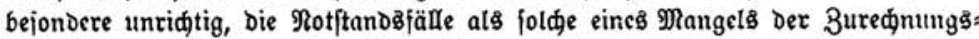

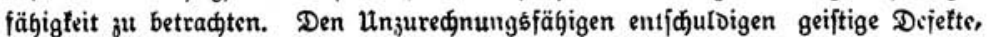
Den iut Notjtand SandeInden aber gerade Der Uniftand, daß̧ fein Berfalten als

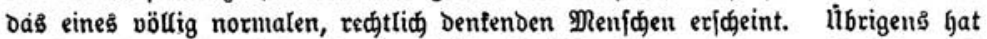

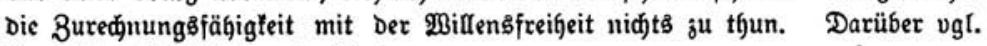
Die fpätere Darjtellung im Tert. 
baraus autalog, baß̧ fie eben in biefen Fällen zum rechtmäßigen \$anbeln unfäbig warent ober fomten fie aud bier nab Belieben

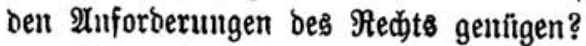

Erft mit biejer Frage fint wir bei bem uns interefiierenden

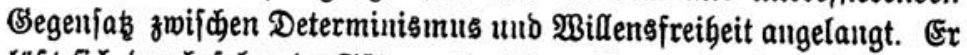

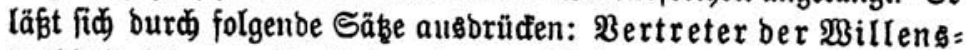
freibeit ift, wer bie Bebauptung aufitellt: Derjelbe Dienif bätte unter genau benjelben ßerbältniffen aud bas Begenteil wollent unb beshalb anders handelı tömuen; ber Berbredjer fpeziell bätte

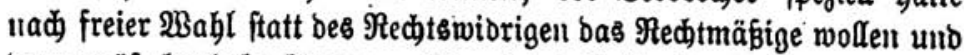
bemgemäß banbeln töment. Wer bies beftreitet, leuguet bie ßillensfreibeit uno ift bamit Determinift, inbem er feiner=

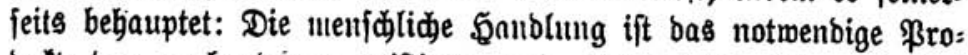
buft ber vorbandenten geiftigen und törperlidjen Eigenart bes Menjiden unter bem Einflußs ber in concreto gegebenten äusern Berbältniffe. Der Mentif $\mathfrak{A}$. in ber Situation $\mathfrak{X}$. founte nur fo wollen und baber banbeln, wie er gebanbelt bat, aber nidjt alibers.

2Hus biefer Begenuiberftellung folgt zugleid: Die Brenze zmifden Willensfreibeit uno Determinismus ift einc baarjdarfe, es Ganbelt fid um ein pindologifdes Entweber-Dber, zwijden weldem es feine Bermittelung gibt. $\mathfrak{B}_{0}$ Bermittehumgeverfuđje in ber Sitteratur auftreten, Lebrt näberes Bufeben betu aud jebesmal, baß̧ ber betreffende ßerfaffer, fofern überbaupt $\mathfrak{f l a r}$ ift, was er meint, fhlieslid) zun Determinismus ober Snbeterminismus ge=

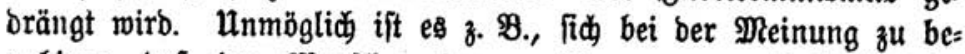

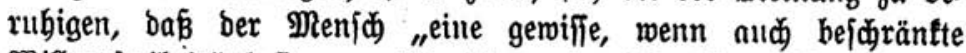

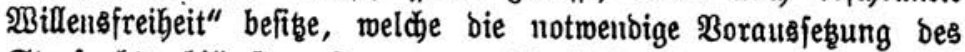

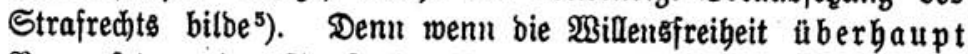
Borausjeşung bes Strafredts ift, fo muk iie natntrlid iu jebem einzelnen Falle vorliegent, in weldem wir ftrafen. Sie beftebt aber in ber Fäbigteit, unter gleichen ßerbältnitfen aud̆ anders

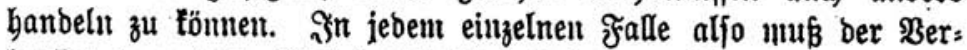
breç)er baun bieje Fähigteit bejeffen baben, aud̆ anbers, nämlid

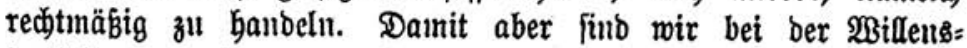
freibeit sans phrase angelangt, für eine bejdräntte $\mathfrak{B i l l e n s f r e i b e i t ~}$

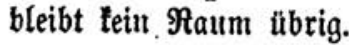

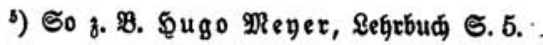




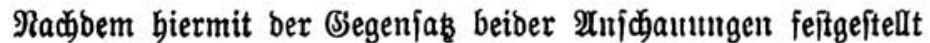
ît, mödters id nuu aber allberjeits betonen: Die Bebeututg bes

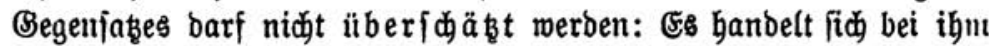
um eite veridjiebene 2Uffaffung über bas 3uftandetommen ber eillzeluen menfdliden \$anblungen, $n i d t$ aber un entgegen:

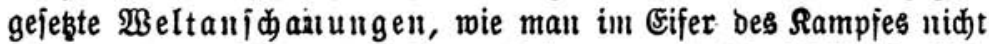

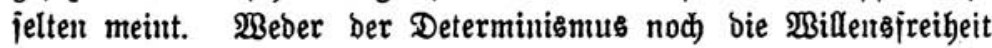
ift an fich eine beftimmte Beltanfdaunturg; es tömten bie ver:

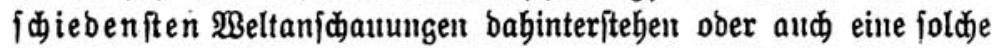
bei beiben थnfiditen gäuzlid feglen. Rekzteres ift ber fall, jo: balb wir eraft miffenfidaftlid verfahren, b. h. jobald wir ftrenty

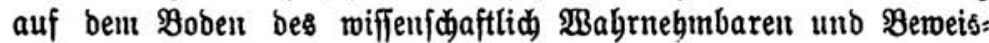
baren ftehen bleiben. Fragen wir baut als Bertreter ber Willens: jreibeit: mie ertlärt fid jente mumberjame Babe bes Menjonen, unter gleidjen ßerbältuiffien etwas Begenteiliges wollen zu tömten, fo lautet bie 2 nttmort einfad): Ignoramus! Zul eitrem Ignoramus aber lommt ftreng wiffenlịaftlid aud ber Determinisimus, nut ipäter. Die einzelne Şandlung erflärt er taujal als Rejultat ber perfönlicjen Eigenart bes Menjijen in ber gegebenen Situation.

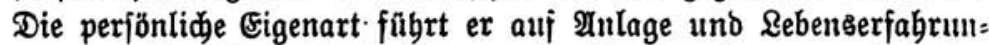
gent zurüct. F̧ür bie Entïtegung ber Inlage fanu er oft, aber fibon feinesmegs inmer anf Einfluffe ber Bererbung vermeijen. Dás aber alle finnlid wabrnebmbaren Einflutfe gerabe eine folde Berjönlidfeit hervorbringen mußsten, welde in ber Situation $\mathfrak{X}$. bie Sanolung $\mathfrak{Y}$. beging, bas fann aud) er nidøt refflos erflären.

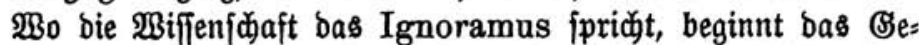
biet bes (Blaubents. Und bier fehent wir, wie bie veridjiebenftut

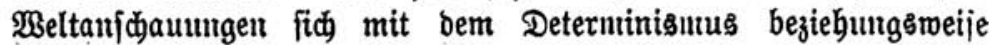
S̈ltbeterminismus vertragen fönnen unt vertragent babch: id fant mir jebr mobl benten, baß̧ ein Sleptiter mid \$ejfinift alles, was im \&eben paffiert, als fimlofent Bufall ertlärelt und gerabe in ber

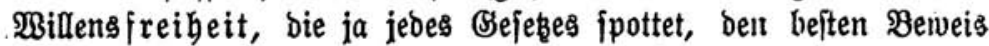

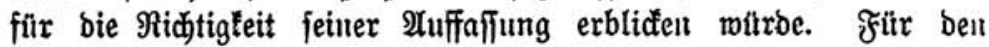
gläubigen Egriften anderjeits famn bie \$illenefreiłeit ein fidjtbares Zeidjen ber (Bröße uno (s)ïte SSottes fein, ber ben Penfiden nad)

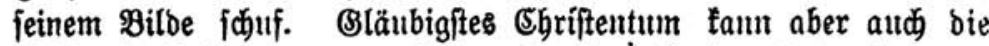
Billensfreibeit leuguen uno ben Stanopuntt des Determinismus

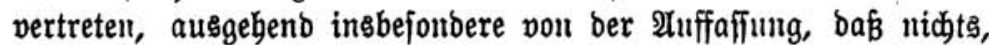
aljo .ud) teine menjoblid̄e Şandlung, ohne ben Willen Brottes ge= 
jobieht, baßs er es ift, ber bie Thaten ber Menfiden in.jebem Einzel=

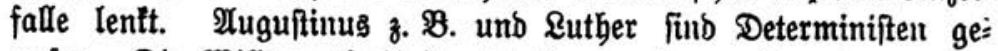
wefen. Die Willensunfreibeit wiro ferner aber and vertreten vom Materialismus, welder alle Erideinutgen aus Bemegungen unঠ 3ujanunenję̧ungen Der Materie erflären zut töınen glaubt. Wieber von völig altberem Stanbpuntte fehen wir einen \$hilojophen von ber Bröbe Sants als 2Anbänger bes Deterninismus: bie Not= wertbigleit ber meniflidien \$andlungen folgt für Sant auts ber

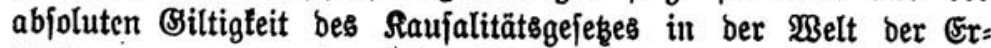
fajeinungen. $\mathfrak{u}_{\mathrm{nt}}$ aber bie Stimme bes Ssewiffens und bas Freibeitsgefübl bamit zu vereinigen, fühte er bie im Bebiete bes Sanbelns nicht vorbanbene freigeit in bem jenfeits unjres $\mathbb{E} r=$ tennerts liegenden, immerften $\mathfrak{B}$ ejen bes Menfiden, in jeitrem Seir. Sinter ben anerfannten Determinismus in ber $\mathfrak{B e l t}$ bes \$anbelns ftellt er fo als Beltanjfanung bie fogenannte intelligible Freibeit bes Menfiden als Dinges an fid.

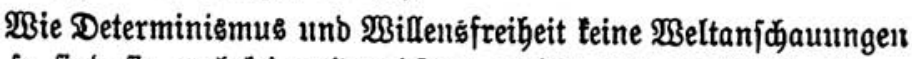
finb, fo finto fie aud teine (s)runbjäz̧e, weldje bas prattifde $\mathfrak{B}$ er= balten bes einzelnen Menfden in beftimmt gegebener $\mathbb{W} e i f e$ be= einfluffen. Denn bie Einfidt, baß̧ bie menfollidje ફ̧andlung fo

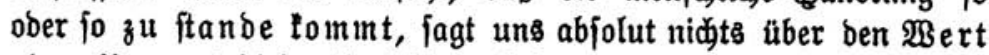
ober Unwert biefer Wanblung, liefert uns aljo feinerlei $\mathbb{P} a \hat{B}=$ ftab bafïr, wic wir banbeln follent ${ }^{6}$ ). Berfennt bies aber jemand

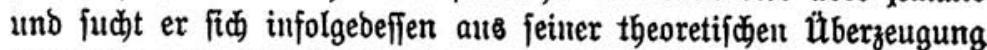
(S)runbjäģe für bie Rebensführung zu fonftruieren, fo werbent bieje wieberum völlig verjøieben ausfallen je nach bem Eharafter bes betreffenten Plenfden. Den entergielofen Schmädjling z. $\mathfrak{B}$. taum

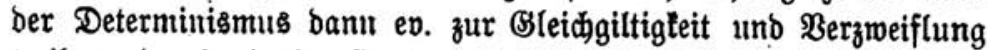
treiben, ba ja boch alles notmenoig und feft gegeben jei. Den ftarłen, energijळen હharałter umgetehrt, welder feine überlegenbeit über bie Mebrzabl ber Mitmentiden fühlt, fann gerabe bie über=

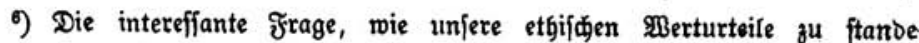
fommen, ftegt gier nidjt zur Dištuffion. F̧ür unjern 3roct genügt bie nega=

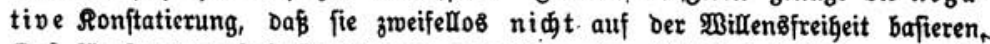

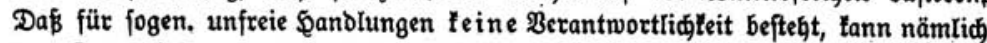

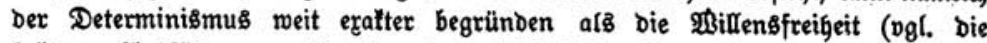

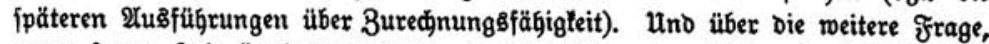
wann fogen. frcie \$anblungen gut, gleidgiltig ober böfe, fpeziell fo böfe

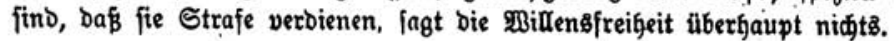




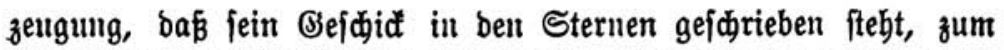
Bertrauen anf feine Sterne und bamit zul ben bödjften uno ibealften Seiftungen anfpornent.

Billensfreigeit und Determinismus fiub alfo weber Beltanfdaungen nod Rebensregelu, fonbern lebiglid verfdiebene Auffaffungen aber bas 3 uftaltotommen ber einzelnen menfdlided Sandlungen. Diefe Einfidyt bemabrt

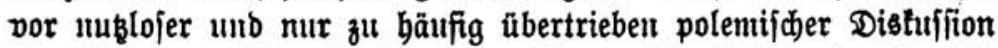
ïber Dinge, welde nidht bierber gebören. Sie bietet anberfeits bie. erforberlide Brundlage, um mumebr ben wirltiden Streitftanto näber ins 2Uuge faffen zu tömmen.

Die Bertreter ber Billensfreibeit $^{7}$ ) argumentierent

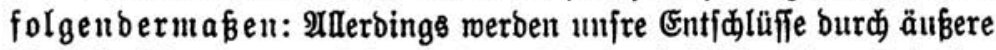
₹erbältniffe mit veraulaß̧t in bem Simue, baß fie obne biefe be: ftimmte äupere Situation vielleidgt nidgt in ber gegebenen 2 seife eingetreten wären. 2Aber: bie äußern ßerbältniffe follicitieren unr, fie neceffitieren nidt, fie bilden mur eine Bebingung aber uidht eine $\mathfrak{u} r\{a d$ de bes Erfolges. D. h. prattifid ausgebrüdt: trokz berjelben Situation bätte berjelbe Menif aud anders rollen und bentgeniäß anberș handeln tömen, als ę gefdah. Der Bemeis bierfiür liegt in bem jebem Menjdjen innewobnenten zweifellofen Befuibl, daß fein 2 ille beim \$anbeln frei ift, fomie in ber untrügliden Stimme bes Serviffetrs, beffen Forberung "but folft" bas "but taunft" vorausjeşt.

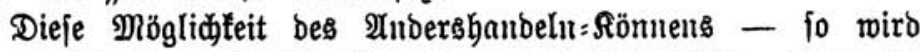
weiter gefolgert - ift bie Brunblage bes Strafredts. Dhne fie

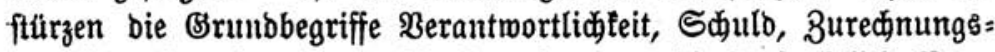
fäbigleit, Bergeltung unb Strafe zufamment: bie ftrafredtlide $\mathfrak{B e r}=$

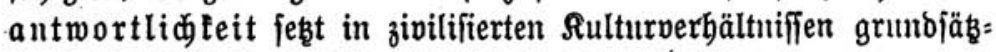

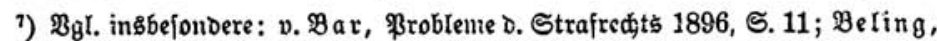

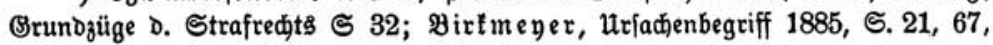
70, 71; Derf. D. Strafgeleşgebung D. Begenwart, Z XVI $97 \mathrm{ff}$; Derf. Beoanten

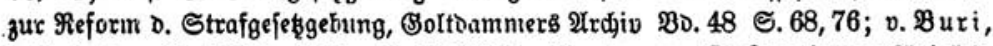

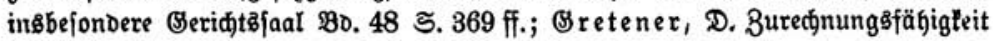

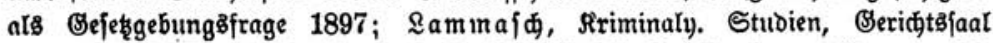

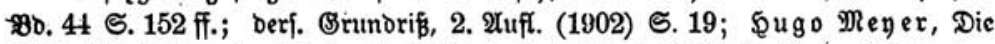

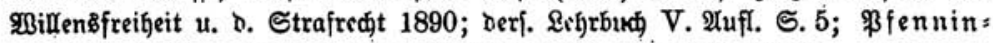
ger, Brengbeftimmungen o. friminaliftifđen Jmputationsిlebre 1892. - Dagegen

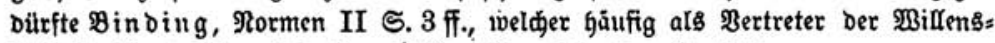
freigeit citiert wiro, vielntegr auf Siantføem Stanopunfte ftehen. 
Iidj ein Beridulbeu poraus; bas Sdauldurteil aber bebeutet einen Bormurf gegenüber bem Thäter. Diefer ßormurf läft fich mur

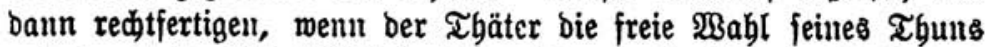

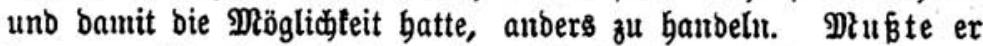
bagegen rectsonibrig hanbeln, bann ift ein Borwurf ihm gegentiber gerabefo unmöglich, wie etwa gegenüber bem Zißgel, ber voim Dache

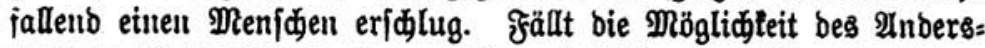
hanbeln= Siönnens fort, bann fält zugleid, ber grunblegende $\mathfrak{u n t e r =}$

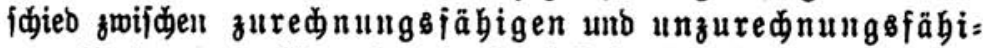

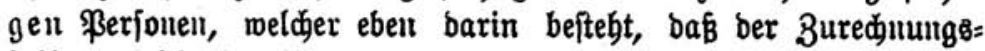

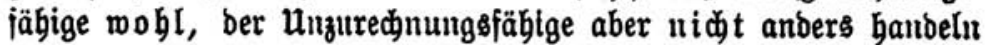
fonnte. Unlo weiter: wie es finnlos wäre, an bem berabfallenden

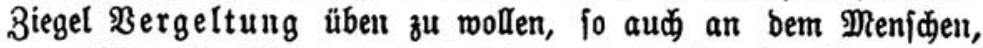
weun feine Salublungen notwendig waren. Jn ber Bergeltumg aber befteht das $\mathfrak{W e j e n ~ b e r ~ S t r a f e , ~ w o ~ f i e ~ m e g i a ̈ l l t , ~ b a ~ f a n n ~ a u d ~}$ von Beitrafung feine Rebe mebr jein.

Bon biejem Şbeengang auşgehe:to ertlären bie Bertreter ber \$illensfreibeit, baß für ibre Begner, aljo für bie Determiniften, mur folgende Ronjequenzent tibrig bleiben: bas Einjfireiten gegen: ïber bem Berbreder läßt fid nidbt als vergeltenbe Beredtigleit

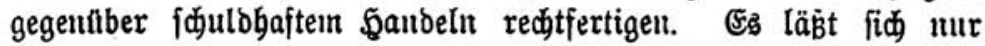
baraulf ftükell, baßs bie Befellfwaft gegen gefäbrlide ßer= jonen gefidjert merbell mub. Diejer Sak aber, jo heibt es weiter, gilt aud gegentiber Bseiftestranten, ja aud̆ gegentuber

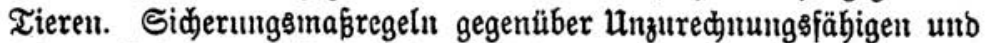
Tieren fint baum aljo in ihrem $\mathbb{B}$ ejen von ber fogenamuten Side: rungsftrafe gegentïber \$erbrechern nidyt verjdieben, ber innere

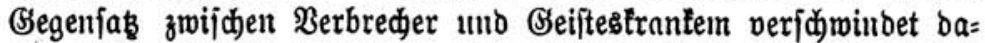
mit. Uno weiter: welu bie Uufgabe bes Strafrechts mur in ber Siderung gegenüber (Befahren befteht, baun ift es folledter= bings uidit einzufeben, warum man erit bie Begehung ftrajbarer Shanblungen abwartet, ehe mant bie, Befellidajt vor bent gefäbr=

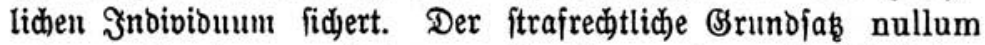
crimen sine lege muß bann alfgegeben umb an bie Stelle ber heutigen frafredtliden Reaftion anf begangene Delifte ein all=

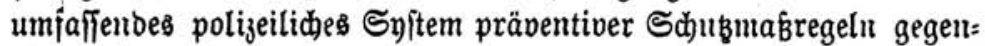
ïber gefährlichen ßerionen gefeşt merben. Rommt es aber bemnod zum Delift, baum barf bie Strafe lebiglid, nach ber Bsefäbrlidjeit Des Thäters, nidjt nad) Der Bedeutung ber Strafthat bemeffent 
werben. Frfd)eint alfo ber Mentid als ungefägrlid, weil Wieber= bolungen für bie Butüuft nicht zu befürchten find, bann tann er iiberbaupt nidjt geftraft merben. Uno umgefebrt: fo lange er

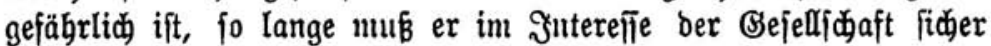
geffellt werben. Daraus folgt bie 9lotmelloigteit, ftatt auf beftimunte

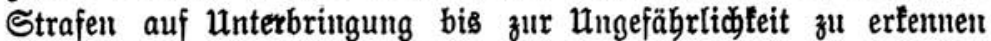
unto bie Dauer ber thatjädlident Detention leobiglid von hen Er= gebniffen bes Strafpollzuges ab̧ängig zu ntadjen. Es müß̄te alfo ber heutige unteridied ber veridiedenten Deliftsbegriffe bejeitigt unb bie beutige ridterlide Strafzumeffung burd fogenaunte un= beftimmte Strajurteile erjest merbelt: Das Strajrecht würbe aus. bem einzigen Saz̧e befteben: jeber gefäbrlide Menifd iit, fo lange feine Befäbrlichteit bautert, unf fäblich zu maçent.

Thatfädlich haben nun manḑe ßertreter Des Determiniosmus, aud) in Deutidlanto, biefe nach 2 Anfidt ber Bsegner eintretenden stonfequenzen in mehr ober wentiger erbeblidjem umfang acceptiert,

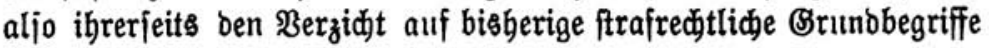
wenigitens teilmeife anertannt. Biemlid meit if in biejer Sinfidht zeitweilig z. $\mathfrak{B}$. v. Lişzt $_{\text {gegangen }}{ }^{8}$ ). Demgegctüber bat nament=

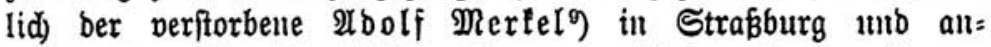
jobliepento an ihn fein Sdjüler Riepmann ${ }^{10}$ ) ben Stanopunft ver= tretell, Daß̧ ber Determinismus feinerlei Beranlajןung hat, foldhe Sonfequenzen zu ziehen, baß́ gerabe er es ift, welder fidy aufs befte mit unfern ftrafredtlidjen (srunbanidauungen verträgt "). Das ift aud meine Deinung, weldje id utnmebr zu entwideln babe.

Der Determinismus jagt: alles, was gejdiebt, unterliegt für umfer Denfen bem Są̧ vom zureidjenten Srrunde. D. h.: wo wir ßeränderungen wahrnehmen, nehınen wir notwentig bas $\mathfrak{B o r}=$

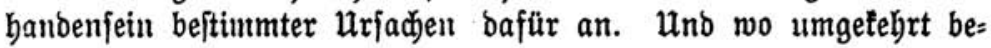

8) BgI. feine 2Uffä̈z̨e Z XIII 325 ff., XVII 70 ff. - Seute bürfte v. Sis̊

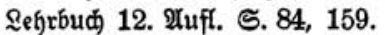

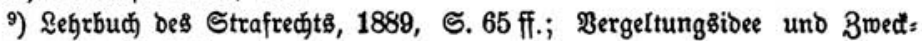
gebante, 1892, S. 52 ff.

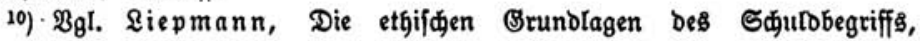

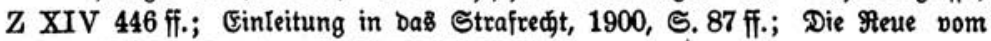
friminaliftifden Stanbpuntt, Z XXII 72 ff.

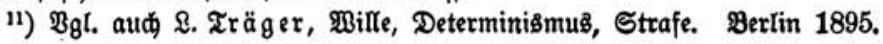


ftimmte urjacjen gegeben finb; treter bie ignen entiprechenbelt Wirtungen ein. Diejer Są̧ gilt, wie für alles Bejejeben, fo auch

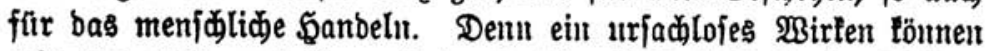
wir uns nidjt vorftellen. Und wie überall bie Ilufgabe ber $\mathbb{B} i f$ en: faraft barin befteht, bie urjaden bes Bejwebens möglidjt auf:

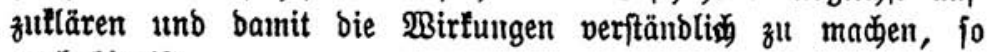
aud bier ${ }^{12}$ ).

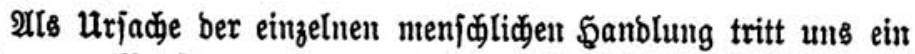
beftimmter Menjळ) it beftimnter Situation entgegen. Den zu= reidenben srund feines Salndelis bilbet baher bie in bem be:

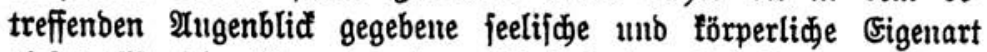
diefes Meniden ${ }^{13}$ ) unter bem Einfluß ber betreffenden äußern Situation, welde in igm feiner Eigenart entipredjenbe Borftellungen und Befüble bervorrief. Sönnten wir bie pindifide \$efdaffenbeit bes Menfiden in bem গ2ugenbliaf vor ber That uno bie Situation, in meldaje er tommt, ftete volftänoig überjeben, fo würoen wir

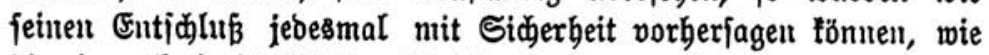

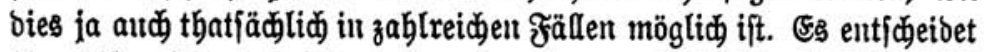
Gier aljo nidst eine felbftänoige unberedjenbare \&röß乃e $x$, ber jreie Wille, fondern erfennbare unto beredenbare gattoren. Jit aber

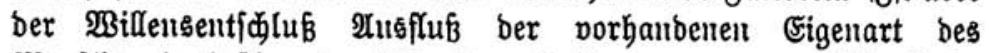

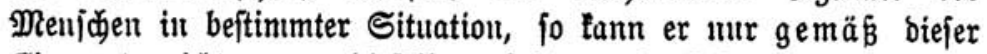
Eigenart, nidt gegen biejelbe erfolgen. Derfelbe Menfid in ber: felben Situation aljo fonnte nur biefen, nidt einen anbern Ent=

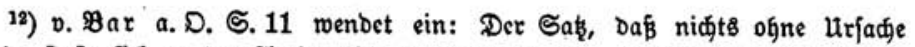

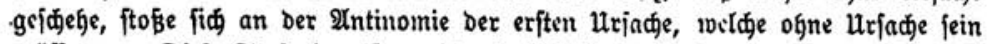
müffe. - Diefe Theje beweift zuvieI: freifid tönnen wir mit unjerm an Raum

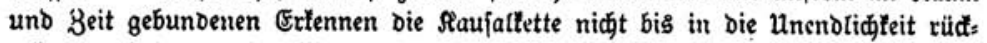

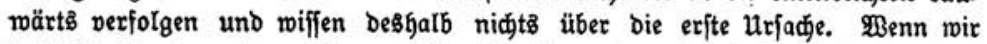

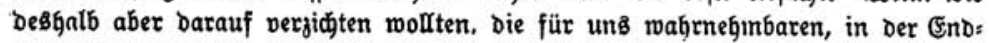
lid)teit gelegenen Eridjeinungen taujal zu ertären, fo würben wir nid)t nur auf

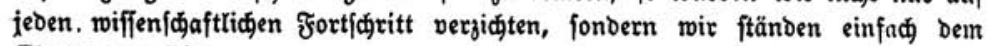
(5)aos gegenüber.

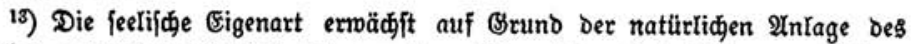
Denifien unter bem Einflús feiner weitern förpertiden Entwidelung uno feiner ¿ebenserfahrungen. Da beide lez̧tern fraftoren nidjt ftabil bleiben, fo mobifiziert

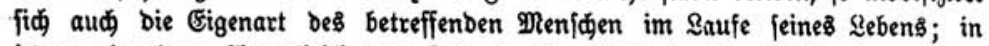
jeoem einzelnen 2Uugenblid besి Lebens aber ftellt fie eine beftimmt gegebene Bröpe bar. 


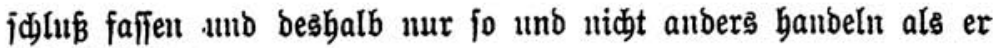
gebandelt bat.

Begen biejen Stanopuntt bes Determinismus ift eingementet

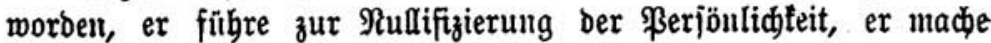

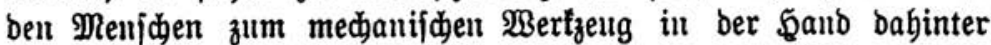

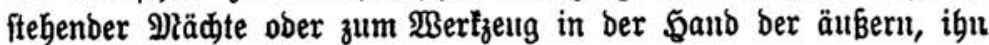
übermältigenten Situation.

Das ift jebod burdjaus irrtümlid): wenu zmei Faftoren A

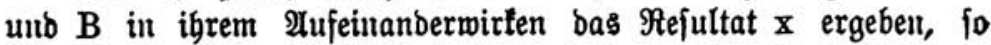
fommt in biejem Rejultat bie entideibenbe Pebeutung jebes einzel= nen biejer beiben Fattoren zum 2luşbruđ, aber nidjt bie জerridjaft eines berjelben über bell anbern. Benaul basjelbe gilt fïr bie

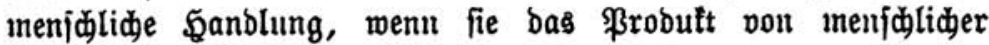
Eigenart unt äuferer Situation ift. $\mathfrak{B i r}$ fegen baum, baß bie

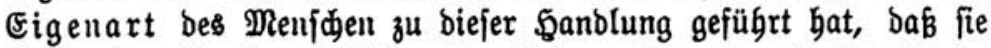
biefes aber allerbings nidit getban babell würbe obne bie betreffende.

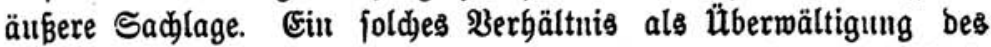
Dieniden burd bie Situation zu bezeidnen, bas ift völlig fdief. Wäre es übrigens ridjtig, jo würbe es genau ebenfo für bie Rebre von ber ßillenङfreigeit gelten müffen, wie für ben Determintisnus. Denu aud bie ßertreter ber Miđlensfreigeit gebelt ja zu, baß bie äußerı ßerbältniffe eine ßebingung für bie ßornabme ber be= treffentien Saltolung waren.

Aluf bie Behauptung ferner, baß ber Menj- für ben Deter:

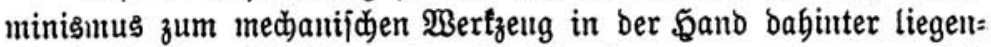
ber Rräfte ober Mächte merbe, ift folgentoes zu ermiderı: welde Siäfte ober Mädhte ben Menjoben zul ftanbe bringen, ob unb in= mieweit höhere Mäd)te im Einzelfalle jein Şandeln lentent, barüber bebauptet ber Determinismus abjolut garnidts; Deul bas. weiß er nidt. Er wäre aber gerwiß äukerīt bantbar, meun bie Rertreter ber $\mathfrak{B i f l e n s f r e i b e i t ~ i g n ~ f r e u n d l i d j i t ~ b a r u ̈ b e r ~ b e l e h r e n ~ m o l l = ~}$ telt. Reiber tönnen fie bas ebenfomenig. Dent bas fint Fragen, weldje, jenjeits ber Brenzen unjres wiffenidajtliden Ertenuens liegent, in bas Bebiet bes rein perï̈nlidben SSlaubents gebören und mit ber wififenjidaftlidjen Streitfrage, wie bie einzelne menjidiche. Şandung zul ftande tommt, überbaupt nidjts mebr zu thut baben.

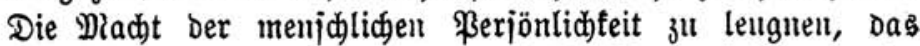
liegt bem Determinismuı völlig iern. Dieje Madjt bejteht Darin,

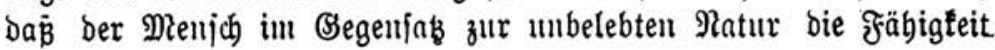




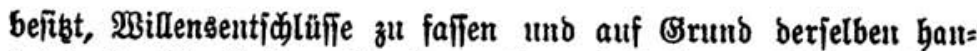
belno in bie 2lukenwelt einzugreifen, baß jerner feine Willens: entiळhlüfTe gegenüber benjenigen ber Tiere in ganz anberm $\mathfrak{u m j a n g}$ burch verftanbesmääige Ermägungen beftimmt werben. Der $\mathfrak{D}$ enf

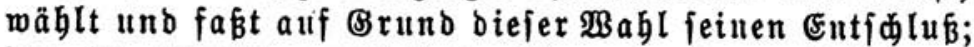
das ift gänzlid zmeifellos. Ulber ebenjo zmeifellos er: fdeint es bem Determinismus, baß ber Menfd eben bas: jenige wählt, was ihm in ber gegebenen Sadlage am ridtigften erfideint, unb baß $i$ gm nidt zugleid bas eille und bas anbre am ridtigiten erideinen tann. Der Denji wäblt aljo, aber er wäblt auf (B) runblage feiner indivi= buellen Eigenart, nidt frei von biejer. Wuf leştere Be=

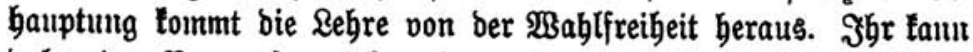
baber ber ßorwurf zurüffgegeben merben, welden fie mit unırecht gegen ben Determinismms erhebt. Sie fübrt zur Rullifizierung ber \$erjönlidfeit. Denn nidjt ber Menjij mit feiner Eigenart hanbelt bier, jonbern ber 3 ufall, welder gerabe fo gut biefen wie bent umgefegrten Entidluß ermöglichte. -

Die eigentlid enticheibenben Berveisgrünbe ber Begner füb bent aud nidt bieje eben miderlegten theoretijden Bebenfen, fon= bern fie furb ber prattificen Erjabrumg entummen: Das jebem Meniden zmeifellos innemohnente ₹reibeitsgefühl bezent bas Borhanbenjein ber $\mathfrak{B a b l f r e i h e i t . ~ U n d ~ b i e ~ e b e n f a l l s ~ u i d t ~ w e g = ~}$ zuleugnende Stimme bes Bsemiffens jekst mit igrer Forberung "Du folft" bas "bu fannft" poraus. Aluf bieje $\mathfrak{A}$ rgumente ift jek̨t näber einzugehen.

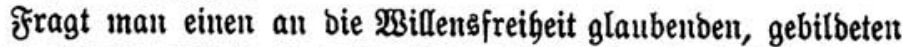
\&aien: Worin bejteht bein Freibeitsgefübl beim \$altoeln? fo er= bält man bas Rejultat: Darin, baß̧ id) thun faul, was id

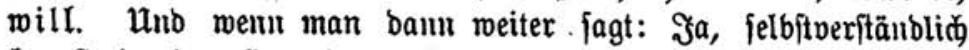
famit bu im allgemeinen thun, was bu willft, biefe freibeit

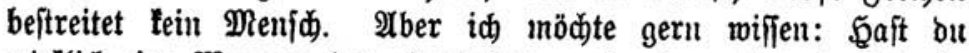

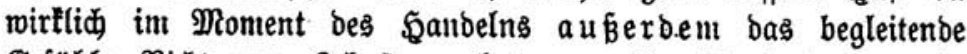

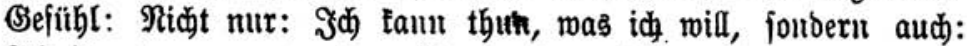

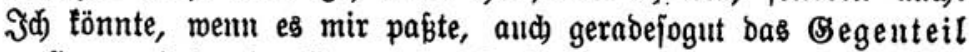
wollen und barin liegt meine Freikeit, baun fodweigt ber Raie, forveit ich beobachten founte, erftaunt uno gibt zu, Daß̧ er iid bieje Frage im Moment bes Sanbelns überbaunt nidit vorlege. Er glaube allerbinge jeşt, wemu er fiđ) bie Sadje überlege, baß er 
auch das Begenteil hätte wollen tönnen. Iber im Ploment bes Sandelns benfe er hieran nidyt.

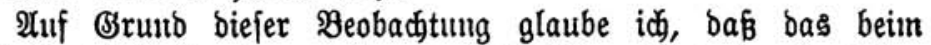
Sanbeln felbjt ipontan, b. h. unwillfürlid auftretentoe Freigeiţ:

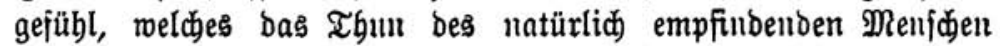
unmittelbar unb unzertrenulidy begleitet, mit ber $23 a b l$ freigeit über= baupt nidits zul thun bat, fondern lebiglide in ber Empfintung befteht, baß bie centralen feelijđjen ßorgänge, weldje unjre Willens: entidlinffe unt entipredjenbe Mustelbervegungen auslöjen, glatt uno ungehinbert von Statten gehent.

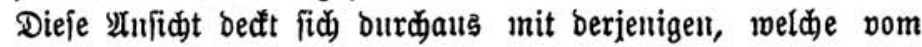
medizinijdent Stanopuntt vor turzem ber \$indiater $\mathfrak{Q} 0$ de $\left.e^{1 t}\right)$ ver= treten hat: Godje nradyt fpeziell harauf aufmerfjam, baß́ ber an Melandjolie leidentbe Sseiftestrante, bei meldjem ber SBebanten= ablauf (in zablemmäßig jeffftellbarer $\mathfrak{B e i j e )}$ verlangfant unb er= fabmert ift uno bie Sörperberegungen eine unverbältuişmäßig groß̧e Billensauppaumung erfordern, gleidzeitig bns ausgefprodene (Be= fübl Der Unlfreigeit babe. Der Sranfe flagt barüber, baß́ jein Bollen gebumben jei, baß er nidjt in ftanbe fei, bas verftandes= mäßig als notwendig Erfannte zu thum. Ulungefebrt zeigt ber an

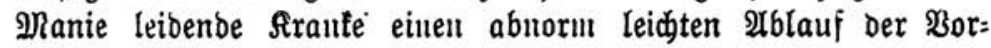

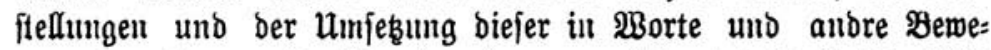
gungen. Dem entipricht ein abuorm geíteigertes Freiheitsgefühl. Dieje Stranten haben bie Empfintong eines jebr leidften uno glüd:

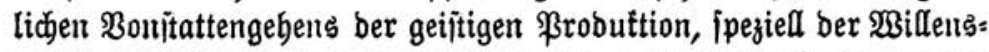
vorgänge. Sieraus in \$erbittoung mit andern Beobachtumgen ${ }^{15}$ ) folgert

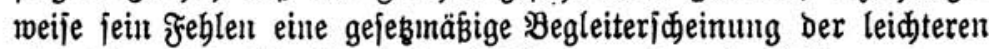

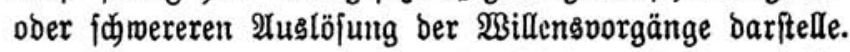

Egiernady formuliere id meine Dleinumg bayin: 1. Das fpontan, ๖. h. unmintürlid auftretende Freiheitsgefïhl beim Şandelı ift nid)t basjenige ber $\mathfrak{B a b l f r e i b e i t . ~ 2 . ~ E s ~ f a n n ~ a u d ~ a b g e j e b e n ~ b i e r = ~}$

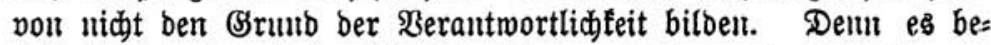
ftegt insbefondere beim Mauiatalifajen, und bennoch ift biefer unt= zurechnungsfäbig uno beshalb uidut verautmortlid.

14) 2 . জode, Die Freiheit beș æillens vom Stanopuntt ber \$indopatho= logie. \$ieşaden 1902.

15) a. D. S. $19-20,33$. 
Wie fteht es nun mit bem burd, Reflexion erzeugten Befühl ber Freiheit, meldjes fid regelmäßig bei Betradjtung it ber $\mathfrak{B} e r=$ gangenheit ober Bufunft liegenber Thaten einjtell (bei abficht= lider Selbftbeachtung aber viefleidyt aud nod im Mroment ber Sandlung felbit fortbauern mag).

Bei Petrachtung fünftiger Situationen zutädit if in ber

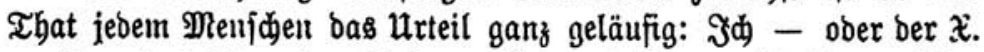
- faum bas Eine ober 2lnbre rollen und bemgemäß thun. Das

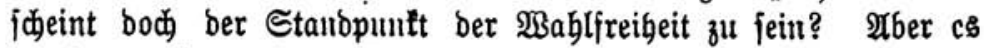
¡めeint aud mux fo. Wenn idy ben zu Thal rollendent Frelsblod beobachte, fo bin id burchaus zul bem Urteil beredigt: Er ta II bie জütte brunten zertrüumerı, er fann aber aud fकूablos vor= überjaujen. Troķbem zweifelt niemant barant, baß̧ ber eine ober anbre 2lusgang, weldjer fdlieflid eintrat, faufal notwentig war. Es hanbelt fich bier einfad) um ein $\mathfrak{N o ̈ g l i d f e i t s u r t e i l , ~}$

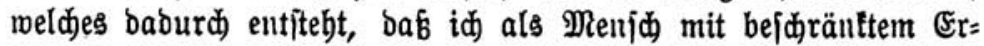
fenmen zur Zeit bie pro et contra mirfenten Bebingungen mur teilmeije überjeben fautu. Der Bebingungsfomplex, ben id über= jebe, geftattet mir nidht, nit Sidjerbeit ben 2 lusgang zu beftimment. Das id ín beftimmen fömute, wenn id fämtlidje Bebingurgent überfäbe, barau zmeifelt aber niemano. SSenau biefelbe Situa= tion liegt vor, wenn id bie Möglidfeit eines verfdie= benen menfdliden Entfdluffes für bie Bufunft be:

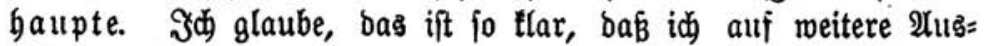
fïthrung biejes Bebantene verzichten bari. (Es entipridbt bem auch

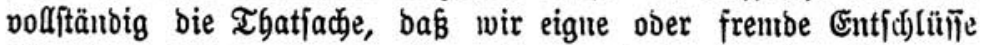
oftmals jo fidjer vorausberechnen tönnell, baß́ wir jeben sinmanto, es tönue bod) auch ein antrer Entjobluß erfolgen, mit ber aller= größten : Beftimmtheit zurüdweijen würben.

Jnl galtz altaloger $\mathfrak{B e i j e ~ e r t l a ̈ r t ~ ( i d ) ~ b a s ~ n a d ) ~ b e g a n g e n e r ~} \mathfrak{T}$ bat jo häufig auftretende Bsefühl, ber Thäter habe aud etwas anbres wollen uno bemgemäß autbers Ganbelı tömten. Diefes $\mathfrak{u} r t e i l$ be:

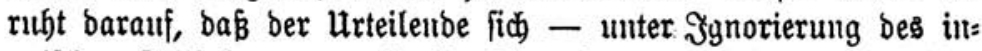
zmijden Bejdebenen - in bie Situation zur Beit ber Entidilie=

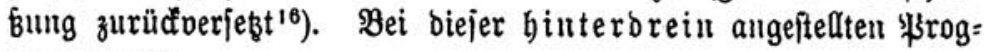

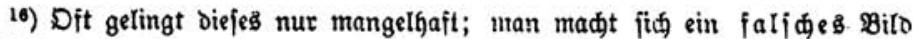

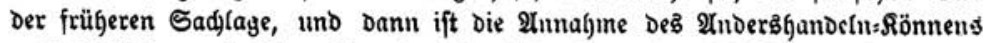

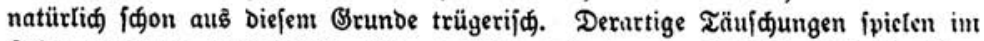
¿eben cine jegr grope Rolle. Sic entftefen entweder Durd) faljde Refonftruftion 


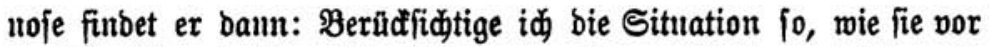
ber ₹gat lag, fo tann id nidjt jagen: (5s mußste baraus ber und ber Entidluß bervorgeben, fontoern uur: Er fonnte barauts her= vorgeben, es tonnte aber aud ein anorer erfolgen. (5) liegt genau ebenio, als wenn ber Reijente bie Thatjadje, baß ber Fels: blod bie Sütte zerjdnretterte, nidt erfahren hat ober ignoriert unb nun beim Meiterwanbern fid fiberlegt: Mubte ber Stein, wie er ba hernieberging, wohl bie ફuütte treffen ober nidjt? Untb ba= rauf antwortet: (Er fonute, er fonnte aud nidjt, wäbrento bas in: zwijhen eingetretene Ergebnis bod taujal notwenbig war. Es Ganbelt fich alfo aud bei biejer rüäwärtigen Petradutung um bas=

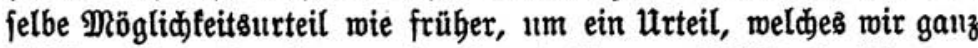

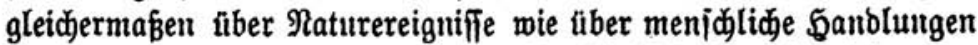
fällen, weldes baher nidht auf ber Wablfreibeit ber Wanblungen im Begenfaßs zu ben Naturereigniffen berubt, fonbern lebiglid

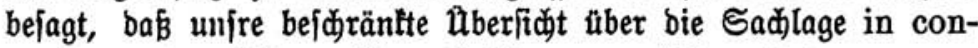
creto zu einer ficheren Borausbeftimmung nidyt gentingte.

Gुiernach lautet mein Ergebnis: Das menfdidide freibeits= gefühl erflärt fid pindologifd befriebigend aus Erifdei= nungen, welde fid mit bem Determinismus aufs Befte vertragen, mit ber $\mathfrak{B a b l f r e i b e i t ~ a b e r ~ n i d i s ~ f u ~ t h u t ~}$ habent.

Diejer 2luffaffung entfprid̈t zugleid volffänbig bie weitere

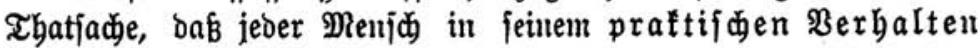
bauerno beterminiftij内e $2\left(n\right.$ idaunumgen betbätigt ${ }^{17}$ ): Wir fuchent andre Menfdjen zu verftehen burd Erforidung ber $\mathfrak{u} r j a d j e n$ ihres

Der früheren objeftiven Sadlage oder bes \& Sefühlşwerts, melden die betreffenden ఇorfteflungen bamals für ben Sandeinden batten. Die objeltiv

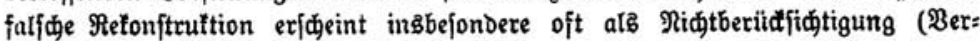
geffen) Damals befannter oder als 5 inzufügen bamals nod unbefannter

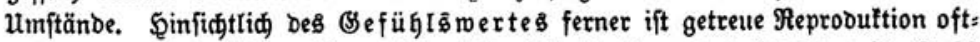

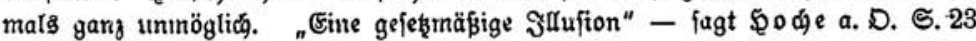
fefre riøtig - "miloert unangenegine Befühjle in oer Eriunerung, färbt gleid): giltige Beiten rojig; vergangene Stimmungen, Ufffette, Befüble tönnen wir uns"

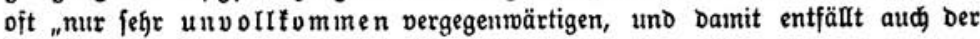
Daşftab, waş fie mohl feinerzeit für eine Stärfe als Wlotiv gegnabt haben mïgen."

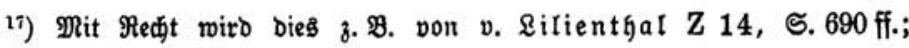
v. $\mathscr{B}$ ü 1 ow Z 16, 582 ff. betont. 
Berhaltents. Wir bered)nen und beeinfluffen ferner bauerno bie Wandlungen andrer Menjden und maden fie bamit unjern 3 wectent oienftbar ebenijo wie bie Rräfte ber ९atur. शraes bas wäre in jebem einzelnen falle unmöglid, wo wir prattij. mit bem freien Willent rechnen würben. Dent befien Eigctutüntid)eit befteht ja gerabe barin, unter gentau benfelben ßerbältniffen aud) bas B Segen. teil berirfen zu tömen, aljo in ber $\mathfrak{u}$ uberedenbarfeit. Freilid

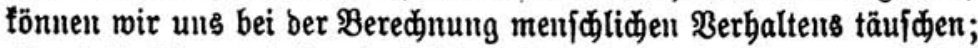
aber lebiglid gerabejo wie bei ber Beredinung fonftiger uatürlider

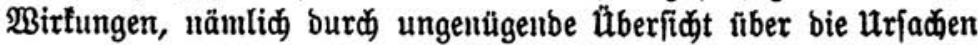
in Einzelfalle. Deshalb lautet im F̧alle einer foldhen Täujdung and

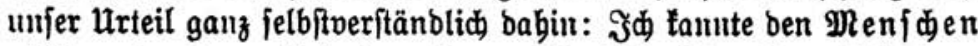
niddt genügent, er if bod anders, als id badjte; aber nidt etwa: Der $\mathfrak{M e n}[$ d) ift fo, wie id aumabm, aber bier bat fein freier $23 i l l e$ gemaltet.

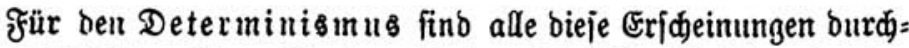
aus natürlid. Bom Stanopuntt ber $\mathfrak{B a b l j r e i b e i t ~ a u s ~ a b e r ~}$

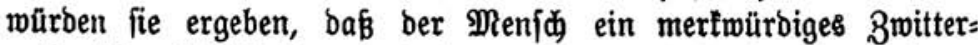
wefen ift: Bablfrei unb bod nach beterniutiftifjen Brunbjäz̧en baltbelutb!

Auch bie Stimme bes Bemiffens, auf weldes fid bie Begner berufent, iit für ben Determinismus burdjaus befriedigeno zu ertlären: Das Berviffen ftellt etbifode 2 nnforberungen an unifer Berbalten ober ridgtiger: Es ift die Summe ethifdjer 2 Unforoerungen, welde unjer Egaratter an unjer Berbalten ftellt. Es tritt uns vor ber That mit ber Forberutg "ou folft" entgegen, und es

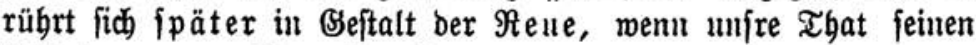
Unforberungent uidit entiprach.

(5) ift aber fojlechterbings nidyt einzufeben, warum bie Forde: rung bes Serviffens "ou folft" notwendig bas "Du famitt" in jebem Einzelfall beweijen foll. Diefe Âmahme wäre vielleidt berechtigt, wemn wir es in bent Bewiffen mit einem ein für allemal gleid̄. bleibenben, fertigen Sittengejes zu thun hätten, meldjes jebem Menlfden eingeboren wäre. Daun tönute man etwa vermuten,

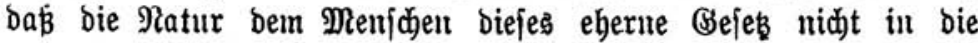
Bruft gelegt bätte, wenu es nidht ein für allemal erjüllbar wäre. Eine joldye 2uffaffug über bas \$ejen bes Bsemiffens aber wiber:

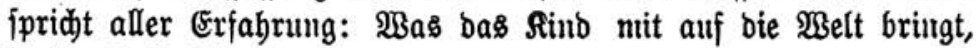
ift bie Fähigfeit, ein Bsewiffen zu erwerben, aber nidjt ein vor= 


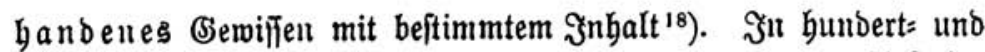
taujendfältiger Wieberbolung müffen biejelben ethijdjen 2Unforbe: rungen an bas Sinto berantreten, ehe fie ans bloben Befeblen von 2Uutoritätsperjonen im Einzelfalle zu eignen Rebensregeln unb gar

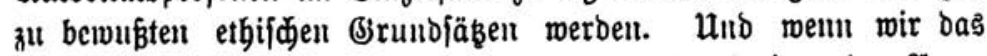
B̈emiffen eines feingebilbeten Europäers mit bemjentigen ber थ̈nge=

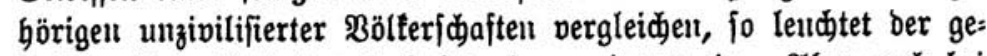

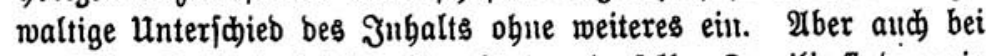
Demiflben ßolfe, ja bei ben 2 ngebörigen berjelben Faunilie funben wir

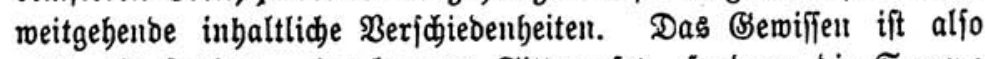
nid)t eill fertiges, eingeborencs Sittengefęs, fonbern bie Summe

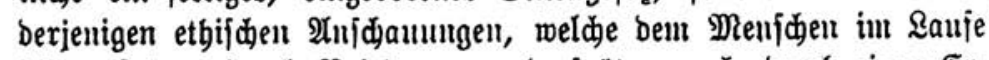
jeincs Rebens burd) Belebrung unı fpäter aud burd eigne Er: fabrung anerzogen worben finb, vielfad wedffelno nad bem Sulturniveau ber Bölter uno Zeiten. Dieje ermorbentu ethi=

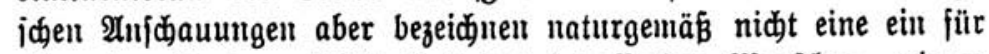
allemal vorbantene Fähigteit bes betreffenden Menjwen, wie es

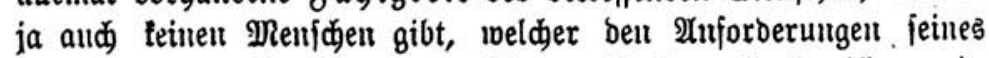
Bemiffents nuڤnabmเรlos genügt bätte. Sondern fie bezeidunen ein Biel, bas etbifde Joeal, bem ber Merrij) nadjitreben foll uno will, fo weit feime Sräfte reidjen, über bej̄en Nidjterreidjung or

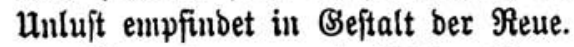

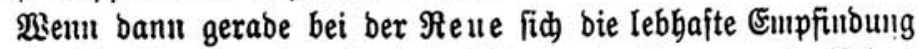
einjtellt: Du bätteft anders gandelı follen unb tömuen, jo ift bas

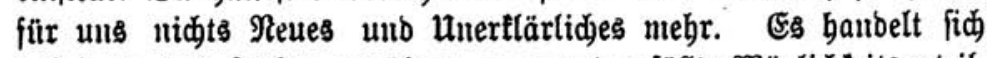
Dabei um bas früber ermähnte, ex post gefälte Möglidłteitsurteil, weldes bier nod fpeziell barauf berubt, baß̄ mir uns mit unjerı jeşigen Empfinoungen in bie frübere Situation zurüđverię̧en unb Die gegenteiligen, bamals zur That brängenden Befüble in

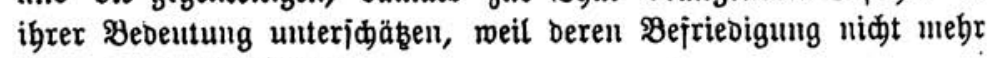
Biel unjers Strebens ijt.

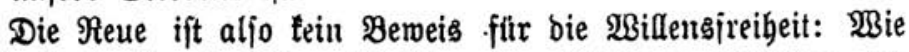
tönnte fie fonft aud bei geiftesf raulen ßerjoncu auftreten, bei

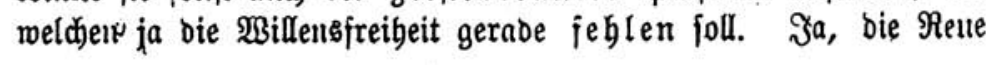

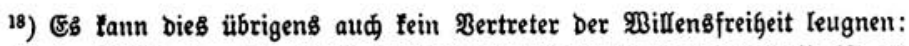

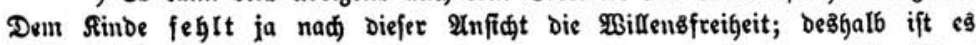

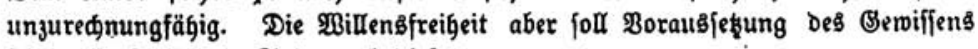
jein; alfo feglt Dem Sinde aud. Diefes.. 
bemeift, wie insbejontere Siepmann ridtig betont hat, birelt gegen bie Millengfreibeit. Denn bie Reue ftell fid obue uno

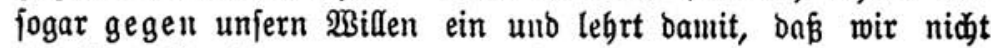
jemeils mollen tömuen, was unt paft.

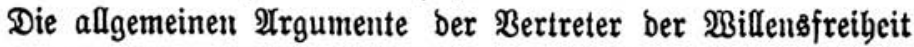
find biermit meines $\mathfrak{B i f f e n s ~ e r j ळ o ̈ p f t . ~ W a s ~ u ̈ b r i g ~ b l e i b t , ~ i f t ~ b i e ~}$ fpeziell ben Ariminalijten interefifierende Bebauptung, baß mur bie

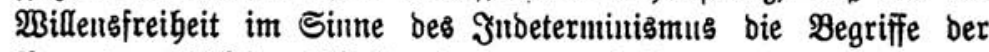
Berantwortlidłfeit, Sđulb, Bureduungsfähigleit, Bergeltung unb Strafe ertlären fömue.

Das Berantwortlid)leitsgefühl bes Meniden berubt, wie Merfel ridjtig betont hat, barauf, baß̉ ber Menij fíd als $\mathfrak{u} r=$ beber feiner Thaten füblt, aljo auf einem taujalen urteil, forwie fermer barauf, baß er nidjt mur über jrembe, fondern aud fiber jeine eignen Thatent etbifd) Berturteile fällt. Deshalb erjodeint es igm natürlidb und ridtig, baß aud) von britter Scite fein $\mathfrak{B e r}=$ baltent entiprechento als gut ober böje beurteilt uno bentgemäß be= Gandelt wiro. Das Berantmortlidfeitègefühl aljo ertlärt fid eraft

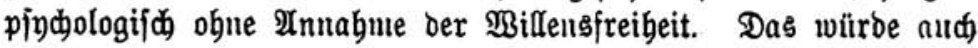
bann gelten, wenn man als meitere Brrutblage bes Berantmort= lidfeits Dent aud biejes hat, wie wir jabent, mit ber \$illensjreibeit nidjte zu thun. Der Determinismus ijt aljo volltommen in ber Rage, bas menjdlide Berantwortlidłeitsgefübl als all= gemeine Borausjebung bes Strafredts zu acceptieren.

Servorzubeben ift Dabei uur, was aud jeoer Bertreter ber Willengfreibeit zugeben muß̧: Daß̧ biejes Bsefühl nidht etwa bent

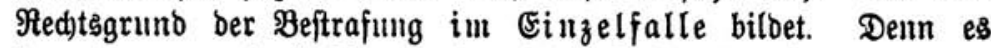
fam in concreto feblen, obwohl geftraft wirb, und es faum umgetebrt beim Bseiftestranten vorhanden fein, aljo in Fällen, wo trok feiner Eriftenz teine Strafe eintritt. Strafredtlide Berantmortlidfeit in Einzelfalle bebeutet aljo nidgt bie Thatjache, daß̧ man fid) verantivortlid) fühlt, fonbern baß man von andern verantwortlid, gemadt wirb, inbem biefe entiprechend, faujale uno Werturteile ïber bie That fälen uno barau als prattifde Folge bie Strafe tuïpfent.

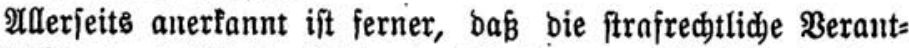

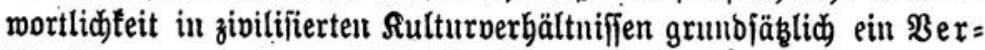

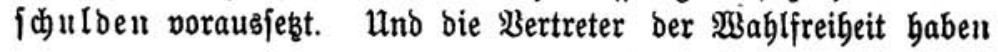


volltommen भiedjt, meim fie ertlären, baß bas Sdulldurteil einen Bormurf bebeute. Es fragt fid mur, worin biefer Borwurf beftebt?

Der Determinisnus entuimmt ben Bormurf gerabe baraus, oa $\mathrm{B}$ bie That bas notwendige Probult ber Eigenart bes betreffen= ben Menjfben unter beftimmten äuberen ßerbältniffen war: Diejer Menj( war es, bei weldem eitre gegebente Situation beftimmte Borjtellumgen erzengte; er war es, für belt bieje Borftellungen einen bejtintmten feiner Eigentart entipredentoen Befübls wert er: langten, berart, baß in bem Sammf ber Befüble pro et contra

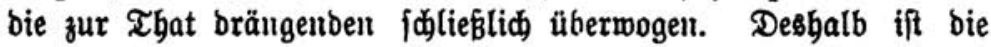

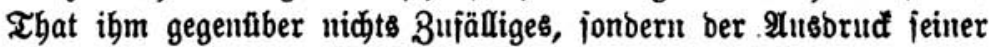
Befimung. Unt beshalb lautet ber burdjans beredtigte ßormuri, meldhen ber Determinisimus erbebt: Du bift ein (d)ledter ober ein ubefonnener $\mathfrak{P e n}\{\Phi$, weil bu bas gethau haft. unb weil bu fdededt ober unbefounen gebandelt haft - nidit weil bu aud umgetehrt bätteft banbeln tönnen - beshjallb ftrafen wir bi ఢ̣. Das aber bürfent und müffen wir beshalb, weil ohne Anbrohung unb Bolzug ber Strafe berartige joblechte ober unbe: formene Thaten it einem $\mathfrak{u m f a n g}$ exfolgen würben, welder jebes

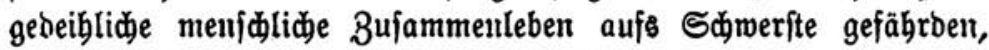
ja überbaupt unntöglid maden mürbe ${ }^{19}$ ).

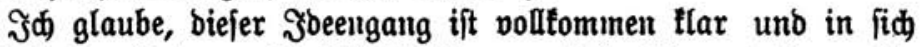
gejdloffent. unto es ift idlechterbings unbeftreitbar, baß er bie Beptrajung vou einem Sdulburteil im Sinne eines Borwurfs abbängig madjt, von bem ßorıvurf nämlidh eines fdblechtent ober

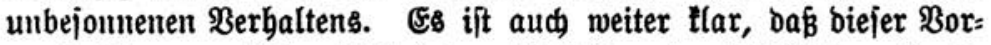

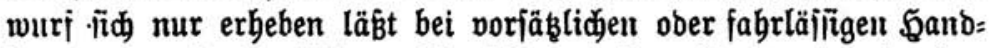

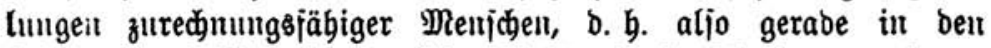
F̧ăflen, in welden bas pofitive Recht ein Beriduldent aunimmt. Der Determinisnus verwirft aljo uidt ben Sdulobegriff

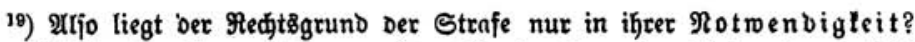

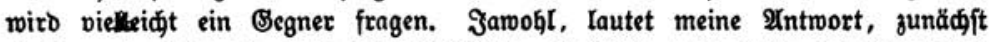
einzig und allein in igrer Rotwendigleit. Beftände biefe nidit, fo mürbe aud

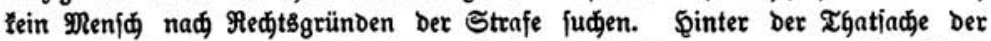
Notwendigleit aber exhebt fí Dann allerbings die Frage, warum bie Strafe notmendig ift? Und braudbare Intworten auf bicfe we itere frage find bann

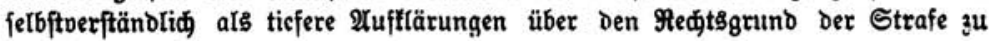
bezeid̄nen. 
Des geltenden Redts, fondern er beftätigt unb ertlärt iG ${ }^{20}$ ).

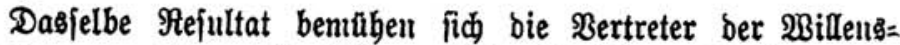
freibeit zu erreident. Die Differenz beiber 2nfiditen alfo liegt nidt in ber Annahme ober Reugnung besె Sdulbbegriffes, fonbern lebig=

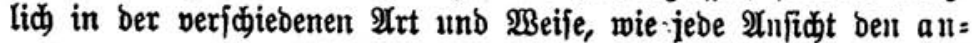
erlantermaben im Sduldurteil gelegenen Borwurf pindo=. logijक zu begrünben verjudt. uno hier haben bie ßertreter ber \$ahlfreibeit zu Dem nidjt felten hervortretenden Siegesbemubtjeiu

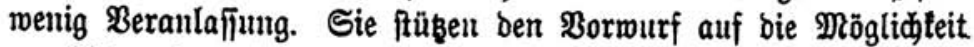
Des थUtbershandelus in concreto. Die Möglideteit aber, unter gleidjen ßerbältniffen anders zu battbeln, würbe bebeuten: Der Menjw ift in ber Rage, benfelben Borftellungen unter gleiden $\mathfrak{B e r}=$ bältniffen einen beliebig veränberten \& efüblsquert beizulegent. Welun basీ wabr wäre ${ }^{21}$ ), bann träte uns in biejem Befiublşwert nidht mebr bie vorbanbene Eigenart biefes Menjwen entgegen, wir fömuten feine Thaten niøjt mebr ans feiner Befinmung begreifen unto fie auf bieje zuridffügren, fonbern fie wären einfach un=

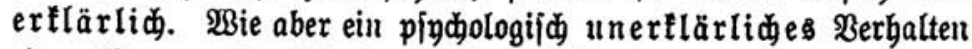
einen Bor wurf rectffertigen foll, oas bleibt unerfinolid.

\$rattijo) verjagt biefer Stanopuntt ber Bablfreiheit ings. befonbere bei ber Bebanblung bes (s) emobnheitsverbreder=

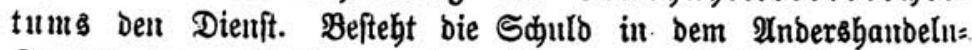
Söunell, baun ift fie um fo größzer uno die Strafe muв um. fo fdwerer jein, je leiditer jemand anders hanbeln fonnte. Der Bemohnbeitsverbreder aber unter bem Einfluß feiner einge wurzelten Bewöbuung faun offenbar - wem überbaupt - mur bejonbers fdiwer anbers banbeln. Man müßte ihn aljo fonfi:

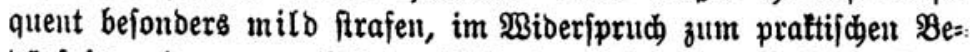

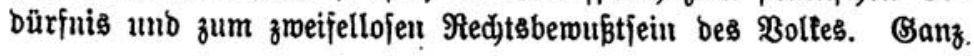

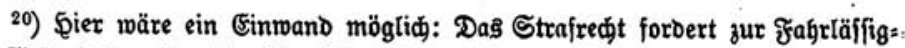
feit pflidgtwibrige Unaufmertfamteit in ben Sinne, Daß̧ Der Thäter den Gerbeis gefügrten Erfolg gätte vermeiden follen und tönnen. Sift biejes "Rönnen“.

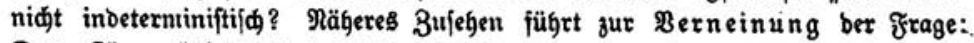

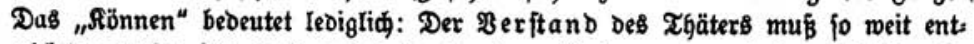

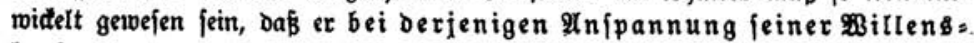
fraft, welde ber Berfegr forbert, daß̊ Fejultat Gätte vermeiden tönnen.

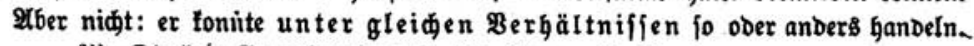

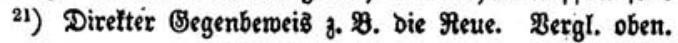


anbers liegt-bie Sadje für bent Determinismus: je fulledter, je unbejonneiter bas Berbalten, um jo größzer bie Sdulb, fo lautet fein Stanopumtt. Der Borwurf bejonberer Sdjledtigleit aber if gerabe bein Beroobngeitsocrbreder begrïnbet, weil ibn

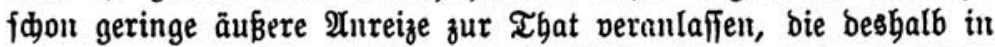

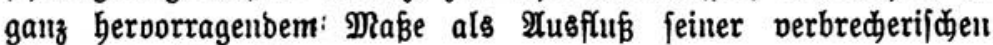
Eigenart er[deeint ${ }^{22}$ ).

Meine bişberigen 2 Uนfü̆brungen laffen wohl fकon erfennen, Daß ber bejonnente Determinismus wie Den Begriff ber Sđjuld $i c$

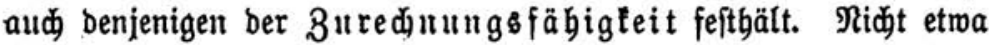
notgebrungen, um ßorwitrfe zul vermeiben, fortoerı weil er einen Dentfebler begeben mürbe, wenn er es nidit thäte. Sebeutet bas

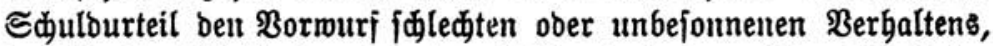

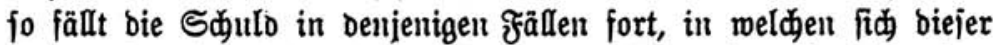
Borwurf nidjt erbeben läß̈t. Das aber ijt nad unjrer heutigent Sulturautffaffung ber Fall, menu Bemußtieinstrübumgen, mangelıbe Berftanbesreife ober frantbafte geiftige Störungen von entideibendem Einfluti auf bas Werbalten bes Thäters waren. Unb biefe fä̆lle

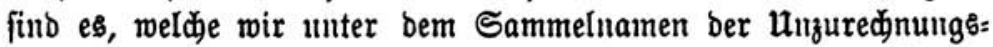
fäbigfeit vereinigen. Siderungsntaßsregeln gegen $\mathfrak{u} \mathfrak{n}_{\mathfrak{z}} u=$

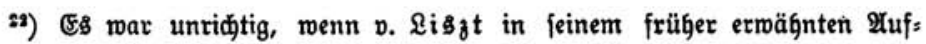
fał über 3ure⿻̆nungşähigłeit (Z XVII 70 ff.) gerade vom Determiniftifden Stanopunfte aus extlärte, bie Buređnungsfägigleit beftege in Der normalen. Bes ftimmbarteit burd Potive, biefe aber fehle bem Bewohngeitso

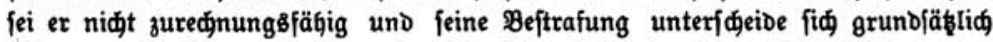
nidit von Der Berwahrung gemeingefägrlider Beiftesłfranter. Darauf ift ju ant:

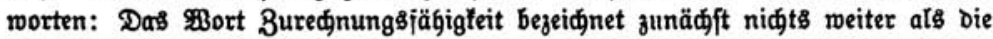
\$andlungsfägigleit auf ftrafredttiden Bebiete, weldje uns auf andern Bebieten

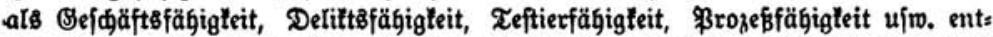
gegentritt. Will man Dieje §andlungşäbigteit „normale Beftimmbarteit Durd Motive" nennen, fo mag man bas thun, in Strafrecht wie fonft. Man erreidt aber bamit weiter niđts, als baß̧ man exflärt, gewöhnli hanblungsfägig. Dagegen gerät man fofort auf Srrrwege, wenı man nun aus biejem ungefähren Sdjlagwort prattifde Ronjequenjen im einzelnen zu ziegen

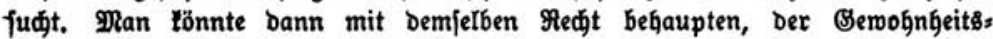

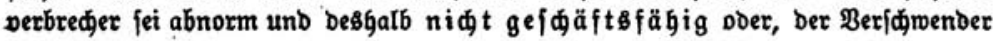

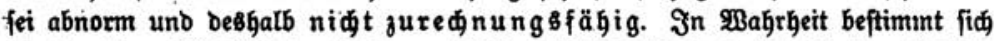

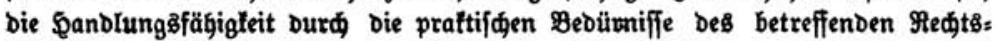

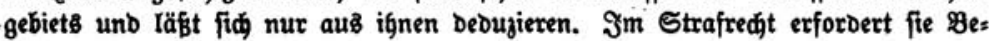
wuftjein, geiftige Bejunbheit und Berftandesireife; und bieje Eigenjळaften befiz̧t

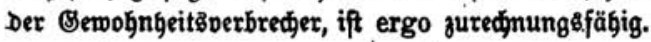


redunungsfähige unterfdeiben fid aljo für bell Determi= nismus von ber Beftrafung Zure⿻⿱㇒扌\zh20ungsfähiger gruno: fäzlid und wefentlid baburd, baß fie tein abfälliges

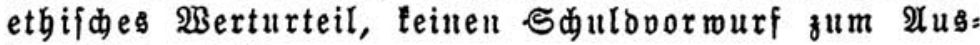
brud bringe ${ }^{23}$ ).

Das ift berfelbe grundlegende Unteridjieb, ben bas Bolfs: berwuftfein empfinbet unb bell aud bie Bertreter ber Millens:

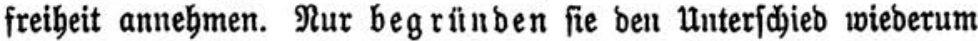
anberø, nämlid mit ber Bebauıtung: Der 3uredumungsfäbige be : ¡ize bie freie Billentsbeftimınung im Sinne Der $\mathfrak{B a b l f r e i b e i t , ~ b e n t ~}$ unıuredumungsfähigen bagegen fehle fie. Deshalb treffe ign fein

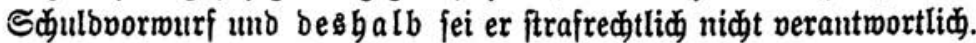

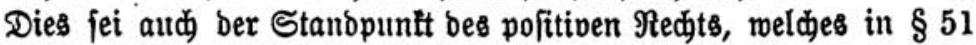

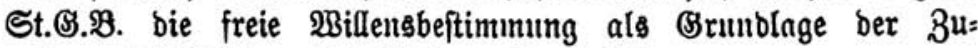
redmungsfähigfeit ausoritülid) anerfaunt babe.

Darauf ift zul antworten: Mag inmerbin ber Befęgeber bei

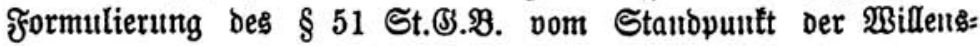
freiheit ausgegangen fein, - was troß bes \$ortlauts bistutabel ift, - jo ift bas bod) felbftneritänolid) leinerlei 'Bemeis für bie

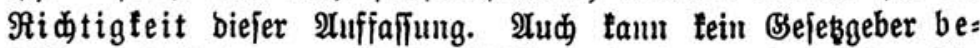
fehlen, baß ber menidlidje $\mathfrak{B i l l e}$ frei ober unfrei fei. Die bindende sebeutung bes sefekeses befteht baher auf alle Fälle lebiglid in ber Boridrift: Bei beftimmten geiftigen Defetten ift

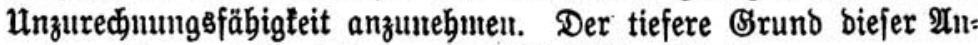
nabme aber unterliegt freier wiffenidjaftlidier ßriffung.

Nun glauben bie Bertreter ber Bablfreibeit, burd bas . Diert= mal bes freien Willens beziehungşmeife burd fein frehlen bie fälle

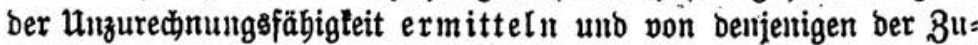
reçnungsfäbigteit fondern zll tömnen. Das aber ift eine Selbft: täufdung; benn woran foll man bent eigentlid prattifd er= fennen, baß́ bie Willensfreigeit beim Thăter vorhanben war

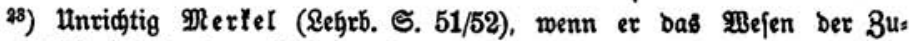

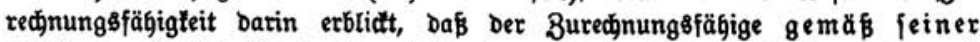
geiftigen Befdaffengeit auf \&nreize reagiere, Daß ex thätig werbe naफ)

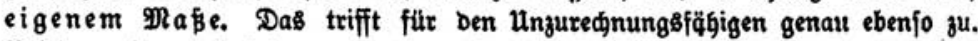
Bei bem einen wie. bei Dem andern ift bie That Das \$rodult feiner Eigenart. Beim unz̧urechnungsfägigen aber ceffiert ber Sđulovorwurf. Das ift bas

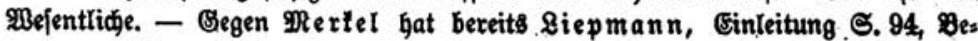

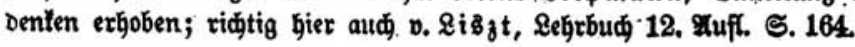




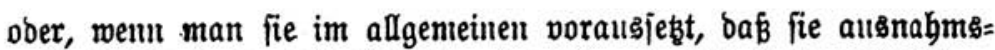
weife feblte? (Es läpt fid feinerlei allgemeines fadjlides firiterium bierfuir angeben uno beshalb ift eine prattifde Ermittelung ber

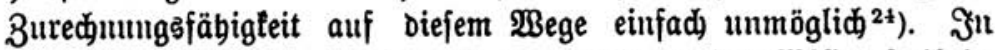
Babrheit verfabren betu aud bie Bertreter ber Billentefreibeit, jobalb iie bie Zurednungşfähigfeit prattijळ prüfelt, burdaus beter= miniftifd. Sie füblen, baß beftimute feftftellbare geiftige Defelte ben Borıurf ber Sajledtigleit ober $\mathfrak{u}$ ubejonnentheit gegenüber bent Thäter ausfjdließen, fein Berbalten als entjouldigt, bie Strafe baber als unangemeijen erideinen laffen. Diefe geiftigen De: fefte ftelfen fie beshalb feft unb erflären fie für maßggebent, genau wie ber Determinismus. Unb babinter ftellen fie bann lebiglid. bie Sypotbeje, baß̧ bei Eriftenz biejer Defette die Millensfreibeit

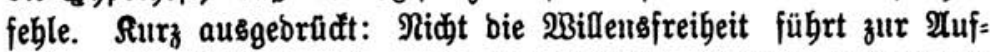
finbung ber f̧älle ber Unzured̆nungsfähigfeit, fonberı bieje fäalle werben nad) anbern, rein prattijisen (sefidstspuntten beftimmt,

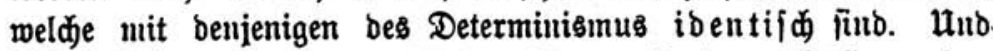

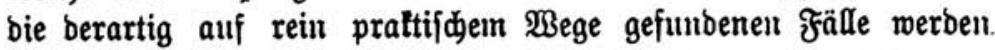

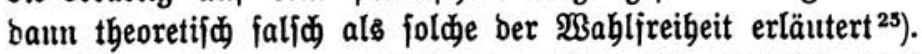

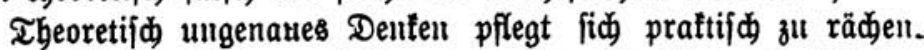
So aud hier. Sind ę beftimmte geiftige Defefte, nämlid $\mathfrak{B} e$ muntfeinsftörungen, mangelnoe Berftanbeß̊reife ober franthafte Störungen ber Beiftesthätigleit, weld)e ben Menjden als unżı= redinungsfähig erfdeinen laffen, fo entftebt als grundegendes $\mathfrak{\text { ro: }}$

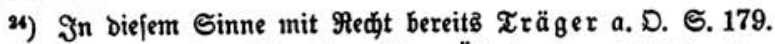

25) Dabei ergeben fid für näbere überlegung nod̆ folgende merfwürdige Sonfequenzen: 1. Die \$illensffreigeit märe teine Babe, welde ber פReníl von. Ratur befig̨t, fondern eine folde, welde ex exft im Reben allmäglid er = wirbt. Denn beim Rinde feglt ja bie 3urednungsfägigteit, aljo die \$illens: freigeit. - Den Erroerb neuter geiftiger (Baben bes \$Renfiden aber tann man bod) eraft beobadten. Warum hier niळt? - 2) Für ben Beifteştranten wäre ber Berluft ber \$illensfreibeit, aljo einer beftimmten, fonft vorbandenen geiftigen

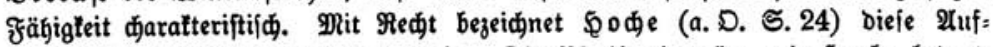

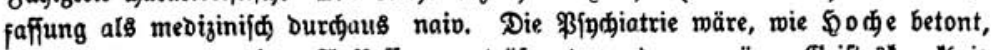
jegr bantbar, wenn jene 2luffaffung zuträfe; Denn bann wären Beiftesిtrantheit

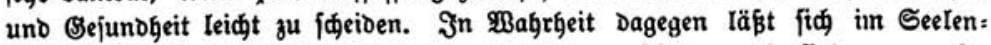

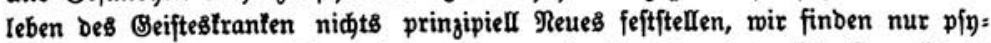
ఉil

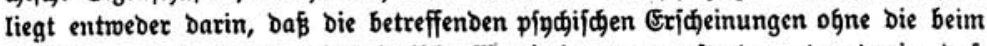
B̈efunden nadweiøbare pindologifde $\mathbb{R}_{0}$ tivierung auftreten, oder barin, Daß̧. fie in ungemögntider Stärfe crídeinen. \$ergl. a. D. S. 28-30. 
blem fofort bie weitere Frage: Belden ơrab müffen bieje De=

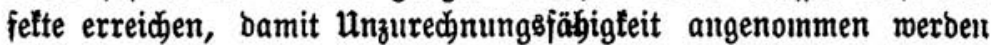
faum? Gier müffen befinmmte, fefiftellbare, fachlidje Sriterien ge: wonuen merben, fonft fteht bie Unterifeibung von Buredunugs. fäbigteit un๖ $\mathfrak{u}$ nzurechluungsfäbigteit in ber \&uft. Die ßertreter

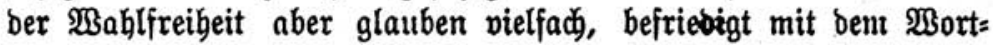
Iaut unires Bejekes, Diefes \$roblem, auf beffen \&öfung bier nidjt näber eingegangen werben tann, mit ber Intwort erlebigt zu

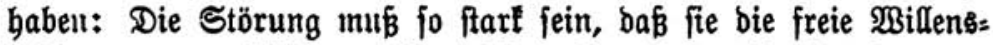
beftimmung ausfobliefit. Mit biejem Saz̧e aber if tein Jota ge= monuen. Denu er ift eine theoretifde Formel ohne jeben praftifa greifbaren Jnbalt. Der Erfolg ift benu aud), baß beute Juturiften wie Mebizituer vor einem groken X fteben, fobalo fie in 3meifels: fällen entjd)eibelt follen, ob irgentoweldbe Störungen berartig erbeb:

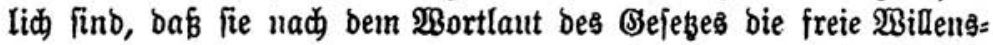
beftimmung ausfjoliefen. Der meitere Erfolg iit, baß́ jeber Teil ain liebften bem anbern biefe Entjaleioung zujojiebt unb baß ber= jentige, meldyer fie fodließlid) trifft, fid babei entweber lebiglid von

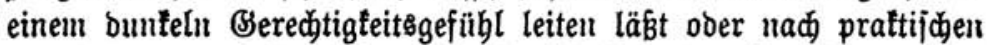

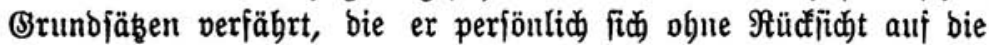
Willengfreiheit zuredjt gemadjt hat uno bie vielleidjt jegr ridhtig, vielleidyt aber auch unzutreffend fint. -

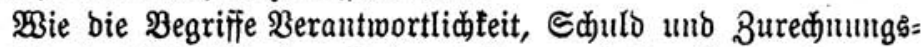
fäbigfeit, fo bleibt für ben Determiniften aud) ber Bergeltungs: zwed ber Strafe in hentigen Simue völlig aujredt erbalten. Freilid) hat hier insbefondere v. Liszt früber einent Bsegenjaks zmifden Bergeltungsftrafe und Bmediftrafe bebauptet und unter Berwerfung ber Bergeltungsftrafe bie angeblid)e 3medijtrafe ge= forbert. (E) ift aber, wie id) glaube, burchaus zmeifellos uno ins: befonbere von $\mathfrak{M e r f e l}$ überzengento bargethan, baß bie Bergeltung leoiglid ciner ber Strafzwede ift, nid)t mehr unb nidjt mentiger,

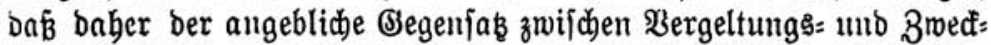
itrafe nidjt exiftiert. Das menidjlidje Bergeltumgsbebürijuis, weldjes iid) in primitiven Beitverbältniffen in (Sefftalt ber rechtlid) ant= erfaututen Blutradje äufert, verlaugt heute vom Stnat, baf er bem Berbrecher ein ütbel zufüge nad) Dlä̧gabe ber objeftiven Bebell: tung feiner That und nach Mafgabe feiner Edullo, o. h. feimer Sd)lechtigfeit oder Unbejounenbeit. Dieịes übel ift uns bas \$flaiter

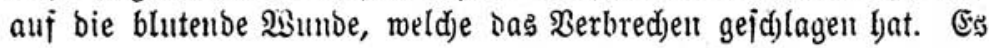




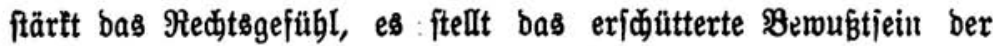

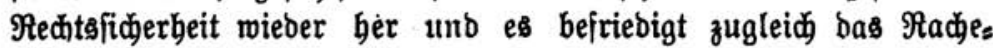
bedutrfnis ber burd̆ bas Berbrechen berührten Sreife, insbefonbere Des Berleķten. Wer biejes Bergeltungebebürinis ignoriert, ber würbe ein Strajredt ¡めaffen, weldes bas Rechtsempfinden bes Bolfes verlekst, anftatt es zu färzfen, uno weldes baher fozial na teilige anftatt whinfonensmerter Folgen hervorruft.

Deshalb ift bie Bergeltung einer ber Strafzmede, uidit, meil ein Strafredt obue Berüfifichtigung biefes Bmedes theoretif $u$ un = bentbar wäre, fonbern weil es praltifid unverftäntoig märe, ein foldes Strafredt ins Reben zu rufer. Berabe ber Deterıninismus,

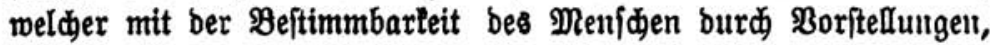
aljo aud nit ben burd bas ßerbrechen und bie Strafe erjeugtent Borftellungen re⿻̆net, un Uno er barf bas thun, obne ein Titelden feiner eiguten ûber=

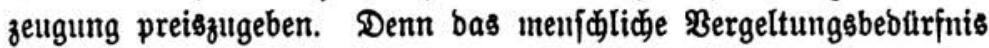
murzelt wabrlic) nidt in ber ફypotbefe ber Willensfreibeit, fonoern auf febr viel realerem Boben. Es ift $\mathfrak{A} u s f l u \hat{B}$ bes Selbit erbaltungstriebes, welder zu gemaltfamer Selbft= bebauptung gegenúber gemaltiamen Berlezungen bräugt.

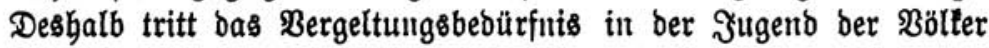

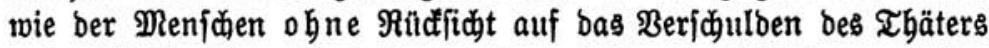
auf. Ee thut bem Berleşten welye unb barum follägt er; ob ber ßerlez̧er etwas bafür tomite, banad fragt er nidjt. Deshalb ferner filloen wir bas ßergeltungsbebuirfnis bei Rinbern und Bseiftes: tranten, bie bod) unmöglid aus bem (stunde biefes Bebürfuis hegen tönuen, weil fie eine bei ihnen felbft nidjt vorbandene Eigen=

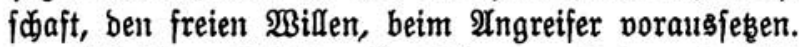

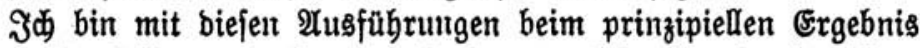
neiner Daritellung angelangt. Es lautet: Die ftrafreditliden (j) runobegriffe Berautwortlidieteit, Sduld, Buredinungs: fäbigleit und Bergeltungsftrafe werben vom Determi= nismus allerfant. Ja, gerabe ber Determinismus glaubt biefe Begriffe allein befriebigenb erflärell zu tönuen.

Mit biejem Rejultat werben bie Folgerungen ber (Begner, baß̧ ber Determinismus wegen \$reisgabe unfrer heutigen \&rumbbegriffe zu rabitalen prattijajen Sonfequenzen gelangen milfie, von jelbjt

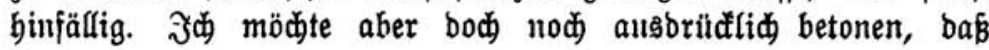


biefe Folgerungen felbft bann faljd) wären, wenn ber Determi=

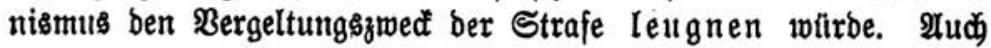
baun würbe er teineswegs zum Erją̧ ber Strafe durd allumfaffente polizeilidje Sidjerungsmaßregelı unb zur \$ebanblung bes einzelnen

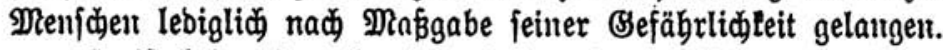

Es if bei unferm heutigen Siulturniveau abjokut ausgefdlofien,

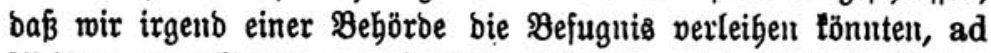
libitum zu ertlären, was fie für gefäbrliđ unto beşbalb ber $\mathfrak{u}$ nter= britưung wultoig bält utub was uidjt. Denn wir wärben bamit

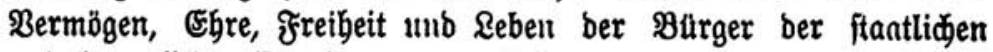
unb beamtlidjen Dmnipoteng ausliefern. Desbalb tönuen polizei=

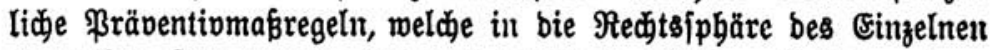
eingreifelt, ftets mur in beftinmt begrenıten Fällen geftattet werben. Und beshalb faum aud bie Strafe als Realtion auf begangentes

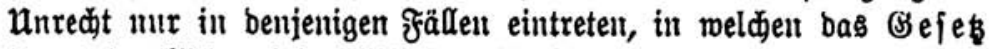

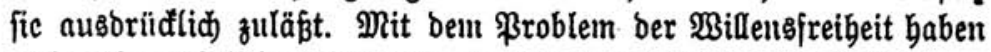

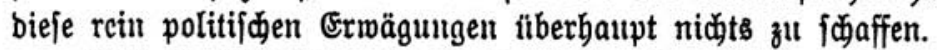

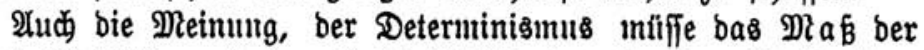
Strafe lebiglid) nad) ber (sefäbrlidjleit bes einzelnen Berbredjers bejtinmen, ift unbaltbar. Ein Determinift, ber bas thut, ift nur eit halber Deterninift. Dent er berïdfichtigt nur bie Beftimm: barfeit bes einzelnen Berbrechers burd bie Strafe aber nidht ben beftimmenten (Einflus, meld)en 2lnbrobung unb Bollzug ber Strafe alf bie Bolfegefamtheit ausüben. Diefe Mtidfidt auf bie Bes famtbeit erforbert bie Beftrafuutg bes Delitts, auch) wemt Der Thäter

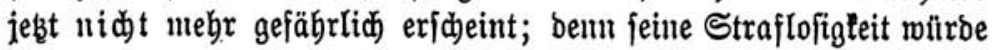
zahlreidje aubre zur $\mathfrak{B}$ egebutg äbnlidber Delitte ermutigen. Die Rtüfficht auf bie Bejautbeit verbietet es ungetehrt, bie ßer: lekzumgen geringer umb wertwoller Rebensgüter gleidi zu beftrafen

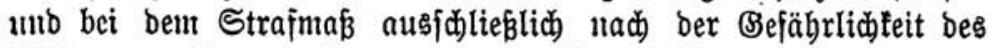
Thäters zu fragen. Denn menu unjre bödiften (süter nur ben= felben Straffidub geniesen witroci wie bie geringiten, fo würbe

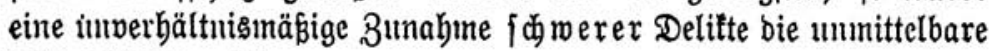
Folge biervon feitr.

Sc) tomme zum Sd)lus. Meine Darftellung follte zeigen, baß ernithafte \$riifung mid zum Deterninisinus, ferner aber audi) zut

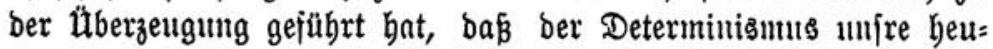
tigen ftrafrechtlichen Brumbbegriffe nidjt nur nicht verwirft, foubern baßs er fie beftätigt und allein befriebigend zul erflären vermag. 
Daß̧ bamit ber Meinungeftreit zwijđen Willensfreibeit und De= terminisిmus in abjebbare : Beit nidt aufbören wirb, bas meiß id. গber id boffe, man wiro fic megr uno ntebr barall gemögnen, bieje \$robleme nidt als Blaubensfachen fonbern als Begenftand nüdterner pindologijd)er (Erörterutg zu behanbeln ${ }^{26}$ ). Uunb bann ¡deint mir eine allmäblide wiffenjwaftlide cinigung aud nidt

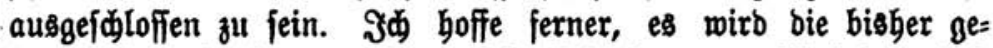

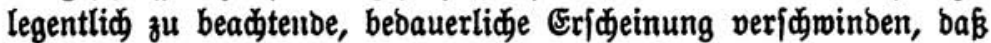
man gegen ben Determinismus als jolden - nidjt gegen etraige

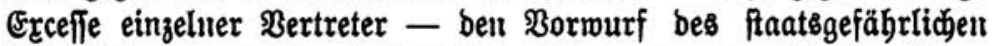

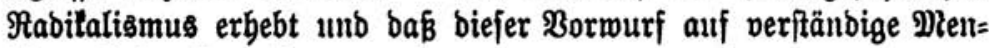
jờen Einoruä madit.

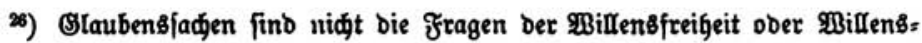

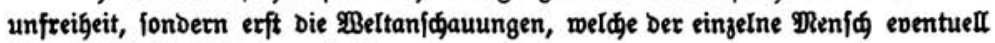
Ginter bieje शuffaffungen ftellt. 